Universidade de São Paulo

Faculdade de Economia, Administração e Contabilidade de Ribeirão Preto

Departamento de Economia

Programa de Pós-graduação em Economia - Área: Economia Aplicada

\title{
Impacto da Lei Seca Sobre a Demanda por Cervejas.
}

Ribeirão Preto 
Prof. Dr. Marco Antonio Zago

Reitor da Universidade de São Paulo

Prof. Dr. Dante Pinheiro Martinelli

Diretor da Faculdade de Economia, Administração e Contabilidade de Ribeirão Preto

Prof. Dr. Renato Leite Marcondes

Chefe do Departamento de Economia

Prof. Dr. Cláudio Ribeiro de Lucinda

Coordenador do Programa de Pós-Graduação em Economia - Área:

Economia Aplicada 
Universidade de São Paulo

Faculdade de Economia, Administração e Contabilidade de Ribeirão Preto

Departamento de Economia

Programa de Pós-graduação em Economia - Área: Economia Aplicada

\section{Impacto da Lei Seca Sobre a Demanda por Cervejas.}

Dissertação de Mestrado submetida ao Programa de Pós-Graduação em Economia da Faculdade de Economia, Administração e Contabilidade de Ribeirão Preto da Universidade de São Paulo, para a obtenção do título de Mestre em Ciências.

Juliana Aliberti Ortiz

Orientador: Prof. Dr. Cláudio Ribeiro de Lucinda

Ribeirão Preto 
Autorizo a reprodução e divulgação total ou parcial deste trabalho, por qualquer meio convencional ou eletrônico, para fins de estudo e pesquisa, desde que citada a fonte.

Ortiz, Juliana

Impacto da Lei Seca Sobre a Demanda por Cervejas./ Juliana Aliberti Ortiz; Orientador: Prof. Dr. Cláudio Ribeiro de Lucinda

Ribeirão Preto, 2015- 145 p. : il.

Dissertação (Mestrado) - Universidade de São Paulo, 2015.

1. Demanda. 2. Imposto. 3. Nested. I. Orientador: prof. Dr. Cláudio Ribeiro de Lucinda. II. Universidade De São Paulo - Campus Ribeirão Preto. III. Faculdade de Economia, Administração e Contabilidade. IV. Impacto da Lei Seca Sobre a Demanda por Cervejas. 


\section{Agradecimentos}

Agradeço ao meu orientador, Prof. Dr. Cláudio Ribeiro de Lucinda, pela paciência e ensinamentos ao longo do desenvolvimento dessa dissertação.

Obrigada aos professores da FEARP/USP, por tudo o que me ensinaram durante o mestrado e por estarem à disposição para contribuirem com este trabalho. Em especial, obrigada à Profa. Dra. Elaine Toldo Pazello pelos diálogos e por contribuir com sugestões.

Também agradeço aos meus colegas de mestrado, pela amizade e convivência enriquecedora nesse momento tão marcante. Em especial, deixo um agradecimento para aqueles com quem mais vivi intensamente: Elder, Vinícius, Caio e Renata, obrigada pelo companheirismo tão fundamental nos momentos árduos e felizes.

Um abraço especial às minhas amigas que permaneceram em São Paulo, porém nunca ausentes nessa empreitada: Vanessa, Thatiana e Débora. Sem o apoio de vocês, essa trajetória teria sido mais difícil.

Aos familiares, agradeço em especial Eclair e Celso, pelo apoio e incentivo.

Por fim, obrigada Lilian, Roberto e Guilherme. Vocês foram essenciais nessa etapa da minha vida, injetando-me motivação e coragem. 


\section{Resumo}

ORTIZ, J. Impacto da Lei Seca sobre a Demanda por Cervejas. 2015. Dissertação (Mestrado) - Faculdade de Economia, Administração e Contabilidade de Ribeirão Preto, Universidade de São Paulo, Ribeirão Preto, 2015.

Com o intuito de reduzir a incidência de acidentes no trânsito, em 19 de junho de 2008 foi promulgada a Lei n 11.705, que enrijece as penalidades aplicadas às pessoas que dirigem sob efeito de bebidas alcoólicas. O presente trabalho trata do impacto sobre a demanda por cervejas subsequente à aprovação da referida lei, cujas punições nela declaradas representam uma internalização de custos que o indivíduo infrator impõe à sociedade. Nesse sentido, buscando inibir o comportamento nocivo à sociedade, a lei gerou incentivos para a queda na demanda por cervejas - bebida alcoólica mais consumida entre os brasileiros. O impacto sobre a compra desses produtos é mostrado neste trabalho, também são estimadas uma função de demanda e elasticidades a partir de um modelo Nested com o objetivo de obter-se um imposto que produziria efeitos equivalentes sobre a queda na quantidade vendida.

Palavras-chaves: Demanda. Imposto. Nested. 


\section{Abstract}

ORTIZ, J. Impact of the Law No. 11,705 Demand for Beers in Brazil. 2015. Dissertation (Master Degree) - Faculdade de Economia, Administração e Contabilidade de Ribeirão Preto, Universidade de São Paulo, Ribeirão Preto, 2015.

In order to reduce the incidence of traffic accidents, the Law No. 11,705 was enacted in June 19, 2008, hardening the penalties applied to people who drive under influence of alcohol. This paper deals with the impact on the demand for beers subsequent to the approval of that law, which stablished punishments in due to internalization of costs that the offender individual imposes on society. In this sense, seeking to inhibit the harmful behavior to society, the law created incentives for the drop in demand for beer - the most consumed alcohol drinking in Brazil. The impact on the purchase of these products is shown in this paper, the demand elasticities estimated from a nested model in order to obtain a tax that would produce the equivalent effect of the fall in the quantity demanded.

Key-words: Demand. Tax. Nested 


\section{Lista de ilustrações}

Figura 1 - Processo decisório . . . . . . . . . . . . . . . . 22

Figura 2 - Regiões de coleta dos dados . . . . . . . . . . . . . 25

Figura 3 - Demanda por cervejas na Área I . . . . . . . . . . . . . . . . . . . . . 29

Figura 4 - Demanda por cervejas na Área II . . . . . . . . . . . . . . . . . . . 30

Figura 5 - Demanda por cervejas na Área III . . . . . . . . . . . . . . . . 30

Figura 6 - Demanda por cervejas na Área IV . . . . . . . . . . . . . . . . . 31

Figura 7 - Demanda por cervejas na Área V . . . . . . . . . . . . . . . 31

Figura 8 - Demanda por cervejas na Área VI . . . . . . . . . . . . . . . . 32

Figura 9 - Demanda por cervejas na Área VII . . . . . . . . . . . . . . . . . 32

Figura 10 - Representatividade das vendas por tipo de envase no Brasil . . . . . . . 33

Figura 11 - Representatividade das vendas por estabelecimento no Brasil . . . . . . 34

Figura 12 - Volume vendido no Brasil na forma de garrafas convencionais em estabelecimentos tradicionais . . . . . . . . . . . . . . . . . 35

Figura 13 - Volume vendido no Brasil na forma de garrafas convencionais em estabelecimentos de auto-serviço . . . . . . . . . . . . . . . 35

Figura 14 - Volume vendido no Brasil na forma de garrafas convencionais em bares 36 


\section{Lista de tabelas}

Tabela 1 - Resultados do Modelo . . . . . . . . . . . . . . 38

Tabela 2 - Elasticidades para Brasil- junho de 2008 . . . . . . . . . . . . . . 40

Tabela 3 - Resultados da simulação de imposto equivalente . . . . . . . . . . . . . 42

Tabela 4 - POF 2008-2009 1 - Adequação às áreas ACNIELSEN . . . . . . . . . . 51

Tabela 5 - POF 2008-2009: Canais de Venda equivalentes a auto-serviços . . . . . 52

Tabela 6 - POF 2008-2009: Canais de Venda equivalentes a bares . . . . . . . . 53

Tabela 7 - POF 2008-2009: Canais de Venda equivalentes a locais tradicionais . . 54

Tabela 8 - POF 2008-2009: Produtos não alcoólicos . . . . . . . . . . . . . . . 55

Tabela 9 - POF 2008-2009: Produtos alcoólicos . . . . . . . . . . . 67 


\section{Sumário}

Sumário ......................... 9

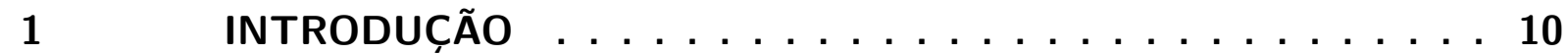

2 O CONSUMO de ÁlCOOL NO PAÍS . . . . . . . . . . 13

3 REVISÃO DA LITERATURA . . . . . . . . . . . . . . . . . . . 15

4 METODOLOGIA E DADOS . . . . . . . . . . . . . 19

$4.1 \quad$ Modelo teórico . . . . . . . . . . . . . . . . . . . . . 19

4.1.1 Efeitos marginais e elasticidades . . . . . . . . . . . . 23

$4.2 \quad$ Dados . . . . . . . . . . . . . . . . . . . . . . . 24

4.2.1 Resposta da demanda por cervejas à Lei Seca . . . . . . . . . . . . . . 27

4.2.2 Imposto sobre bebidas . . . . . . . . . . . . . . 36

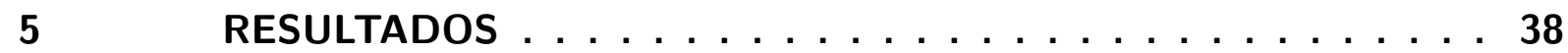

$5.1 \quad$ Elasticidades . . . . . . . . . . . . . . . . 40

$5.2 \quad$ Simulação . . . . . . . . . . . . . . . . . . 42

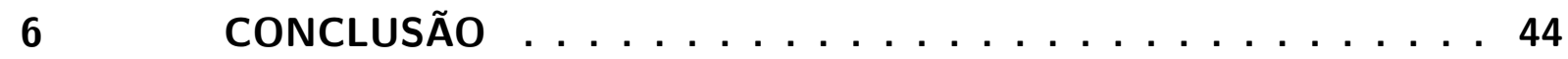

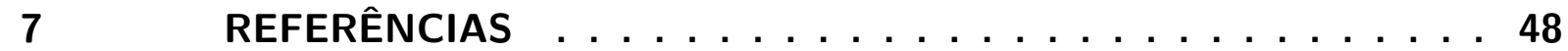

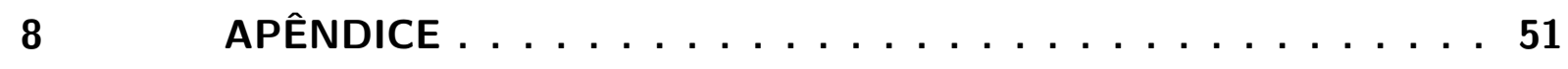




\section{Introdução}

O presente estudo tem como objetivo avaliar o impacto sobre a demanda de cervejas devido ao enrijecimento das penalidades aplicadas aos condutores de veículos automotores sob o efeito do álcool. De acordo com o I Levantamento Nacional sobre os Padrões de Consumo de Álcool na População Brasileira (2007), o consumo de cervejas representa $61 \%$ do total de bebidas alcoólicas consumidas no país.

Com o intuito de reduzir a incidência de acidentes no trânsito, em 19 de junho de 2008 foi promulgada a Lei n 11.705, que enrijece as penalidades aplicadas às pessoas que dirigem sob efeito de bebidas alcoólicas. A adoção dessa medida fundamentou-se em dados da Associação Brasileira de Medicina de Tráfego (Abramet), que reconhece a ingestão de bebidas alcoólicas como responsável por 30\% dos acidentes de trânsito. Ainda mais, de acordo com o Ministério da Saúde, metade das mortes no trânsito estariam relacionadas ao uso de álcool por motoristas.

A nova Legislação, conhecida como "Lei Seca", alterou os artigos 165, 276 e 277 do Código de Trânsito Brasileiro. De acordo com o artigo 276, estariam sujeitos a penalidades quaisquer condutores em que fossem encontrados álcool no sangue, em qualquer concentração. O condutor que for alvo de fiscalização ou estiver envolvido em acidente de trânsito, sob suspeita de dirigir sob a influência de álcool será submetido, com base no artigo 277, a testes que verifiquem seu estado, como o teste de alcoolemia. Para detecção da presença de álcool no indivíduo pode ser aplicado o teste de sangue em laboratório ou o teste do etilômetro, também conhecido como "bafômetro". Esse equipamento identifica a quantidade de álcool no organismo a partir da análise do ar expelido pelos pulmões.

A presença comprovada de álcool no sangue do condutor seria considerada infração gravíssima pelo artigo 165 da referida lei, com aplicação de sete pontos na carteira de motorista, multa de $\mathrm{R} \$ 957,70$ (valor superior a dois salários mínimos, que na época equivaliam a $\mathrm{R} \$ 415,00$ cada) e suspensão do direito de dirigir por 12 (doze) meses, além de retenção do veículo. Caso fosse encontrada concentração de álcool superior a 0,30 mg, 
a infração seria considerada como crime de trânsito. Como consequência, o condutor estaria sujeito a penalidades adicionais, como detenção de seis meses a três anos, multa e suspensão ou proibição de se obter a permissão ou a habilitação para dirigir veículo automotor.

Todas essas medidas têm o intuito de responsabilizar o infrator sobre os efeitos negativos de suas ações para a sociedade. Embora os modelos econômicos se baseiem na hipótese de agentes racionais, é reconhecida a incapacidade de o indivíduo internalizar todos os efeitos de suas atitudes, adicionando-se o fato de os eventos estarem dispersos no tempo. Quando trata-se da relação entre alternativas e consequências, pode-se distinguir entre a relação tal qual o tomador de decisão observa (subjetiva) e a relação que efetivamente ocorre (objetiva). A conexão entre as expectativas dos tomadores de decisão e as reais decorrências de suas escolhas é limitada pela falta de conhecimento dos agentes a respeito das circunstâncias correntes e de conhecimento científico (SIMON, 1997a). ${ }^{1}$

Uma vez que as pessoas reagem a incentivos, fazer com que o infrator arque com custos referentes às externalidades negativas por ele causadas é uma forma de inibir o mau comportamento. No entanto, essa não é a única política pública possível, como será visto mais adiante. A análise sobre a demanda por produtos alcoólicos já foi explorada pela literatura internacional e serve de insumo para o desenho de políticas públicas, como será visto ao longo do trabalho.

Para o início da investigação do impacto da Lei Seca sobre a demanda por cervejas, mostraremos os hábitos de consumo etílico no paíss e seus impactos sobre a saúde pública. Discorreremos sobre os comportamentos de risco e como as cervejas estão relacionadas a estes, em especial, no que se refere a acidentes de trânsito. Na seção 3, fazemos uma revisão da literatura especializada, de modo a reunir as políticas sociais adotadas internacionalmente para reduzir hábitos de risco.

Em seguida, a seção 4 trata da metodologia utilizada para obtenção das elasticida-

1 "in actuality, the human being never has more than a fragmentary knowledge of the conditions surrounding his action, nor more than a slight insight into the regularities and laws that would permit him to induce future consequences from a knowledge of present circumstances." (SIMON, 1997a, p. 78) 
des preço-própria e preço cruzada. Também são apresentadas as informações utilizadas, o processo de tratamento dos dados e algumas estatísticas descritivas. Na seção 5 são apresentados as elasticidades obtidas e os resultados das simulações. Por fim, a seção 6 traz as considerações finais do presente trabalho. 


\section{O consumo de álcool no país}

O consumo de bebidas alcoólicas tem se mostrado um importante problema de saúde pública. Estima-se que o consumo nocivo de álcool seja responsável por cerca de $3 \%$ das mortes que ocorridas no mundo, na forma de doenças ou acidentes causados [Meloni e Laranjeira, 2004]. Nos países em desenvolvimento, incluindo-se o Brasil, o impacto negativo dessa substância seria ainda mais preocupante: aponta-se a ingestão do álcool como causa de aproximadamente $8 \%$ a $15 \%$ dos problemas de saúde nessas nações. (Meloni e Laranjeira, 2004; World Health Report, 2002). Essa grande dimensão pode ser compreendida quando se analisa os dados de consumo dos brasileiros.

De acordo com o I Levantamento Nacional sobre os Padrões de Consumo de Álcool na População Brasileira feito pela Secretaria Nacional Antidrogas (SENAD, 2007), 52\% dos brasileiros acima de 18 anos ingerem bebidas alcoólicas pelo menos uma vez ao ano, sendo que o consumo é mais representativo entre os homens (65\% dos homens e 41\% das mulheres bebem). Tratando-se apenas daqueles que ingeram ao menos uma dose no ano, tem-se que $60 \%$ dos homens e $33 \%$ das mulheres consumiram 5 ou mais doses numa só ocasião, ao considerar-se a situação em que mais beberam no ano - o que induziria um comportamento de risco. O consumo entre adultos do sexo masculino foi considerado frequente (consumo de bebida alcoólica de 1 a 4 vezes por semana) para $28 \%$ e muito frequente (consumo diário) para 11\% da amostra. O estado de consumo de risco (beber em binge) é estabelecido como a ingestão em uma única ocasião de 5 doses ou mais para homens e 4 doses ou mais para mulheres (Brewer e cols., 2005). Essa prática estaria associada a diversos prejuízos físicos, sociais e mentais (Naimi e cols., 2003) dados os efeitos do álcool etílico no organismo. Dentre as modificações neurofisiológicas sofridas pelo indivíduo estariam desibinição comportamental, comprometimento da capacidade cognitiva, diminuição da atenção, piora da capacidade de julgamento e redução da coordenação motora.

Para compreender o quão extenso é o problema, o estudo da SENAD aponta 
que cerca de $17 \%$ das mulheres e $38 \%$ dos homens assumiram comportamento de risco durante o ano de 2007. No total, $28 \%$ da população brasileira adulta teria bebido em binge ao menos uma vez no ano, o que significa 33,6 milhões de pessoas em nível de intoxicação. O levantamento mostra que a cerveja é a bebida mais consumida entre os brasileiros, representando $61 \%$ do consumo total de bebidas alcoólicas. Adiciona-se a esse fato que a cerveja é o tipo de bebida mais frequentemente associada ao binge. De todas as doses ingeridas por aqueles que beberam de forma abusiva no ano, $73 \%$ foram de cerveja. O estudo conclui que $12 \%$ da população adulta possui algum problema com álcool (uso nocivo e dependência), o que seria um índice significativo em se tratando de saúde pública.

Quanto ao problema social de ingerir bebidas alcoólicas e dirigir em seguida, 46,6\% dos homens e 13,6\% das mulheres declararam ter dirigido ao menos uma vez sob o efeito do álcool no período de um ano. Um fato que merece destaque é a recorrência do comportamento de risco dentre aqueles que assumiram a transgressão. Aproximadamente dois terços dos brasileiros adultos que dirigiram alcoolizados já o fizeram por duas ou três vezes após a ingestão de 3 doses de álcool no ano analisado. Isto é, os indivíduos que dirigem alcoolizados apresentam altos níveis da substância no sangue e repetem o comportamento de risco ao longo do ano, aumentando, portanto, a probabilidade de acidentes. Ademais, há de se ressaltar o valor expressivo de pessoas que sujeitam-se ao deslocamento com motoristas alcoolizados. Segundo o estudo da SENAD, 34\% da população adulta geral declarou ter estado na posição de passageiro em um veículo no qual o condutor havia bebido excessivamente. O combate a esse comportamento nocivo à sociedade já foi feito em outros países por meio da adoção de diversas políticas, como mostra a seção a seguir. 


\section{Revisão da Literatura}

Diferentes políticas referentes ao consumo de álcool seriam capazes de impactar negativamente a ocorrência de acidentes fatais de trânsito, como a redução da concentração de álcool no sangue permitida em condutores de veículos automotores ou a elevação do limite mínimo do consumo de bebidas alcoólicas para 21 anos conforme DeJong e Hingson (1998) afirmam.

Uma das políticas destacadas pelos autores é a aprovação de uma lei que permitisse a apreensão imediata da carteira de motoristas de condutores constatadamente alcoolizados. Essa medida teria sido responsável pela redução de $5 \%$ a $9 \%$ dos acidentes fatais de trânsito, aliada, evidentemente, à fiscalização. Nesse sentido, o efeito da implementação de pontos de fiscalização rotativos também teve destaque no estudo sobre efeitos em acidentes de trânsito.

De acordo com os autores, houve uma redução de 17\% nas mortes com causas relacionadas a álcool no tráfego apenas pela maior fiscalização de trânsito no Tenessee, com bloqueio de vias públicas. Em um ano, 150 mil condutores de veículos automotivos teriam sido abordados por pelo menos um dos 900 postos de controle, fazendo aumentar a percepção de risco de apreensão da licença para dirigir daqueles que ingeriam bebidas alcoólicas. Esse programa teria sido amplamente divulgado por redes televisivas, o que explicaria pelo menos em parte de tamanho impacto.

Aliados à fiscalização, efeitos da redução da Taxa de Álcool no Sangue, como a Lei Seca brasileira estabeleceu, são uma forma efetiva de reduzir acidentes fatais no trânsito, ainda de acordo com DeJong e Hingson (1998). Isso porque, comparando-se estatísticas de estados que experimentaram a redução do limite da TAS de 0,1\% para 0,08\% com estados em que não houve essa redução nos EUA, constatou-se que a maior rigidez da Lei fez reduzir $16 \%$ os acidentes fatais.

Os autores também relatam o efeito da Lei com a proibição do consumo de álcool 
de jovens com menos de 21 anos. Isto é, haveria uma camada da população apta a dirigir porém proibida de consumir álcool. Observou-se que a Lei de tolerância zero para jovens dessa camada fez com que acidentes fatais envolvendo jovens de 15 a 20 anos de idade caíssem em 20\%. Em contrapartida, estados que adotaram limites mais baixos de TAS para essa camada da população, sendo 0,04\% contra 0,1\% para a faixa etária superior, não surtiram efeitos sobre a queda de acidentes.

Uma explicação dos autores seria que Leis de tolerância zero transmitem uma clara mensagem sobre a ilegalidade de dirigir após qualquer nível de bebidas alcoólicas. Isto é, no que conferem as medidas de segurança no trânsito, o efeito dissuasor das leis de tolerância zero dependem da consciência geral alcançada. A interpretação da mensagem, internalização dos custos à sociedade é requerida para que os efeitos dos programas de combate a comportamentos nocivos surtam redução de externalidades negativas. Esse é o papel dos incentivos, sejam eles maior fiscalização do cumprimento da Lei ou aumento de impostos como desincentivo.

No que tange às providências a serem tomadas a respeito dos infratores, Taxmana e Piquero (1998) testaram a efetividade de dois tipos de políticas: reabilitação ou punição severa. De acordo com o primeiro tipo de abordagem, os transgressores careceriam de tratamentos para conter o uso e abuso de álcool por meio de intervenções públicas. A ênfase é colocada em abordar o comportamento subjacente do uso de álcool, que contribui para novos incidentes de dirigir alcoolizado.

Por um lado, a reabilitação procura mudar o comportamento do infrator que não consegue internalizar os custos de seu comportamento, oferecendo sessões de terapia e programas educacionais. Por outro, as punições cumprem o papel de desestimular o tipo médio de condutor a assumir um comportamento de risco ao volante, estabelecendo sanções e/ou ameaça de punição como multas e restrições de licenças para dirigir. Disposto de outra forma, as reabilitações procuram tratar o problema subjacente ao álcool e inibir a ocorrência do mesmo delito futuramente, enquanto as punições mais severas fariam uso de ameaças de sanções legais para deter condutores sob o efeito da substância . Os resultados mostraram que ações de caráter reintegrador têm o potencial de reduzir a reincidência 
bêbado dirigindo e que punições mais severas não mostraram-se vantajosas.

O desestímulo ao consumo de bebidas etílicas nos EUA, por sua vez, é um certame histórico de suma importância. A experiência desse país em proibir o comércio de bebidas alcoólicas fracassou a ponto de produzir contrapartidas negativas evidentes, sendo mundialmente conhecida. Em resumo, entre 1920 e 1933, os cidadãos dos Estados Unidos da América ficaram sujeitos ao The Noble Experiment que proibiu a venda, fabricação e transporte de bebidas alcoólicas. ${ }^{1}$ Se por um lado a famosa Lei Seca conseguiu reduzir problemas relacionados ao consumo da substância, por outro, o governo viu seu apoio público ruir devido à demanda contínua de produtos alcoólicas e do desenvolvimento de mercado ilegal para sua aquisição. Nesse sentido, procurou-se um redesenho das políticas de desestímulo ao consumo, não como proibição mas com aplicação de impostos, por exemplo.

A partir de estudos sobre a entrada da juventude no mercado consumidor e de acidentes de trânsito, homicídios e suicídios relacionados à ingestão de álcool etílico, foi possível compreender com maior clareza medidas que reduzissem o consumo médio da população em geral. Dessa forma, era esperado atingir também a porcentagem da população que consome em níveis excessivos, onde estariam a maior parte dos problemas relacionados à substância.

Sabendo que os indivíduos possuem preferências intrínsecas ao mesmo tempo que reagem a incentivos para fazer suas escolhas, a sensibilidade do consumidor a preços é um objeto de estudo importante para o desenho de políticas que combatam o comportamento individual nocivo à sociedade. Mais especificamente, no que tange a demanda por cervejas e outras bebidas alcoólicas, é sabido que o consumo cai como resposta ao aumento de preços. Por esta razão, o aumento de impostos sobre esses produtos confere uma estratégia de prevenção a acidentes de trânsito.

Saffer e Grossman (1987 a, b) avaliaram o impacto do aumento de impostos incidentes em cervejas sobre a probabilidade de acidentes fatais de trânsito nos Estados Unidos a partir de um painel no intervalo 1975-1981. Os resultados do estudo mostraram 
uma correlação negativa de um aumento de impostos sobre essas bebidas com a ocorrência de acidentes fatais envolvendo jovens de 15 a 24 anos.

Tratando-se de impostos, Manning, Blumbergb e Moulton (1995) afirmam que a medida eficiente deve considerar o trade-off entre os ganhos econômicos e sociais de se colocar os indivíduos que consomem álcool de forma abusiva frente aos preços que reflitam totalmente os custos sociais de suas ações, com os efeitos adversos sobre o aumento dos impostos para aquelas pessoas que consomem com moderação. Os resultados da estimação mostraram que os consumidores que bebem pouco e moderadamente respondem mais efetivamente às variações de preços, isto é, apresentam demanda mais elástica. Dessa forma, a imposição de taxas que desencorajem o consumo abusivo de álcool acarreta em perda de bem estar daqueles cujo consumo não externaliza custos à sociedade.

Nesse sentido, é possível estimar um imposto com efeitos equivalentes sobre a quantidade demandada que outras políticas impõem. Para tanto, faz-se necessário estimar as funções de demanda demanda e as elasticidades preço própria e preço-cruzada. O ponto de partida será um modelo de escolha discreta em dados agregados. 


\section{Metodologia e Dados}

\subsection{Modelo teórico}

O modelo de escolha em ninhos traz à luz a decisão do indivíduo entre consumir ou abster-se sob a hipótese de que as alternativas são mutuamente excludentes. Dessa forma, o consumidor optará pela alternativa que lhe proporcionar a maior satisfação possível e sua escolha do indivíduo pode ser segmentada em etapas, o que reduz a necessidade de dados disponíveis. Nesse sentido, é importante compreender as características das alternativas que atuam como fatores determinantes de escolha dos consumidores, considerando que há fatores em comum entre indivíduos.

Com esse modelo, serão determinados os componentes que efetivamente afetam a probabilidade de escolha do consumo de cerveja, resultando em um modelo probabilístico que relaciona esta probabilidade às características dos indivíduos e dos tipos de cerveja consumidos. (TRAIN, 2009; LOPES e MOITA 2013),

É sabido que a utilidade do indivíduo é não observável, mas suas escolhas sim. Dessa forma, podemos analisar a tomada de decisão a partir dos atributos dos produtos e das características do tomador de decisão. A escolha do indivíduo é feita de acordo com atributos observáveis dados por $x_{j}$ e não observáveis, $s_{j}$, além de um componente aleatório específico ao indivíduo e ao produto $\varepsilon_{i j}$. (TRAIN, 2009)

Dessa forma, a equação de escolha será dada por:

$$
U_{i j}=V_{i j}+\varepsilon_{i j}
$$

sendo $V_{i j}$ a parte determinística da utilidade e $\varepsilon_{i j}$ um componente aleatório. Ademais, podemos reescrever o termo determinístico $V_{i j}$ como combinação linear de coeficientes, $\beta_{j}$, e características, $x_{j}$. Desse modo, o fator de sensibilidade específica do consumidor aos atributos observados $x_{j}$, é representado por $\beta_{j}$. Essa sensibilidade pode ser modelada 
por meio da interação entre as características dos indivíduos e do produto. Os atributos não observáveis que interferem na decisão do consumidor são representadas pelo termo $\xi_{j}$ e o termo aleatório da utilidade é dado por $\varepsilon_{i j}$.

Podemos utilizar dados agregados levando-se em conta que a probabilidade de escolha de um indivíduo por uma marca pode ser aproximada pela participação de mercado deste produto. Sendo assim, a demanda de mercado para o bem j em uma economia com N consumidores será dada por:

$$
Q_{j}=N \times P_{j}
$$

sendo $P_{j}$ a probabilidade de escolha do produto, igual entre consumidores.

A participação de mercado em número de unidades vendidas será dada por

$$
s_{j}=\frac{Q_{j}}{\sum Q_{k}}=\frac{N P_{j}}{N}=P_{j}
$$

De acordo Train (2009), uma importante ressalva há de ser feita. Até o que foi apresentado até o momento, supondo-se que haja apenas dois bens no mercado e que o preço de ambos caia marginalmente, a quantidade demandada ficaria inalterada. Essa situação não é verossímil, por isso, uma hipótese adicional deve ser feita para solucionar esse problema. Vamos considerar a escolha do consumidor por não comprar nenhum dos bens em questão como uma opção possível, isto é, a não aquisição dos bens em questão confere um terceiro bem. A parte determinística da utilidade deste bem, por sua vez, será normalizada em zero:

$$
s_{0}=\frac{1}{1+\sum_{k \neq 1, \in J} e^{V_{k}}}
$$

e para outros bens:

$$
s_{j}=\frac{e^{V_{j}}}{1+\sum_{k \neq 1, \in J} e^{V_{k}}}
$$


Então, podemos escrever

$$
\ln \left(s_{j}\right)-\ln \left(s_{0}\right)=V_{j}=\mathbf{x}_{\mathbf{j}} \beta_{\mathbf{j}}+\xi_{j}
$$

Tratando-se do Nested Logit, temos o agrupamento de produtos similares em grupos. Partindo da premissa fundamental de escolha do consumidor, assume-se que os indivíduos possuam necessidades por caracteristicas auferidas dos bens. Desse modo, a aquisição do pacote de atributos do produto implica em satisfação ao consumidor. Lembrando que

$$
U_{i j}=V_{i j}+\varepsilon_{i j}
$$

sabendo-se que no modelo aninhado, algumas alternativas compartilham os mesmos elementos entre si nos termos representativos da parte aleatória da escolha do consumidor, teremos uma correlação entre componentes aleatórios da utilidade de algumas alternativas. A definição dos ninhos para análise do impacto da Lei Seca sobre a demanda por cervejas terá como base o processo decisório em duas etapas, conforme mostra a figura 1. O tomador de decisão escolhe primeiro a marca, e em seguida analisa as diferentes embalagens deste grupo. Nesse sentido, se o consumidor tem preferência pela garrafa de 600 mililitros da marca A, então é provável que a garrafa de um litro da cerveja da mesma marca seja um substituto mais próximo do que a opção em lata, que contém apenas 350 mililitros. Lucinda (2013)

O presente estudo foi feito com dados agregados e, por isso faz-se necessária uma adaptação. Particionaremos o vetor $x_{j}$ em dois componentes: um deles representando o preço do bem e o outro agregando todas as outras características, ou seja $\mathbf{x}_{\mathbf{j}}=\left[p_{j} \overline{\mathbf{x}_{\mathbf{j}}}\right]$ Ademais, pode-se separar a sensibilidade da demanda para variações de preço e de outros atributos:

$$
U_{i j}=\alpha p_{j}+\overline{\mathbf{x}}_{\mathbf{i j}} \beta_{i j}+\xi_{j}+\varepsilon_{i j}
$$

O termo $\varepsilon_{j}$ representa as características não observadas pelo econometrista, en- 
Figura 1: Processo decisório

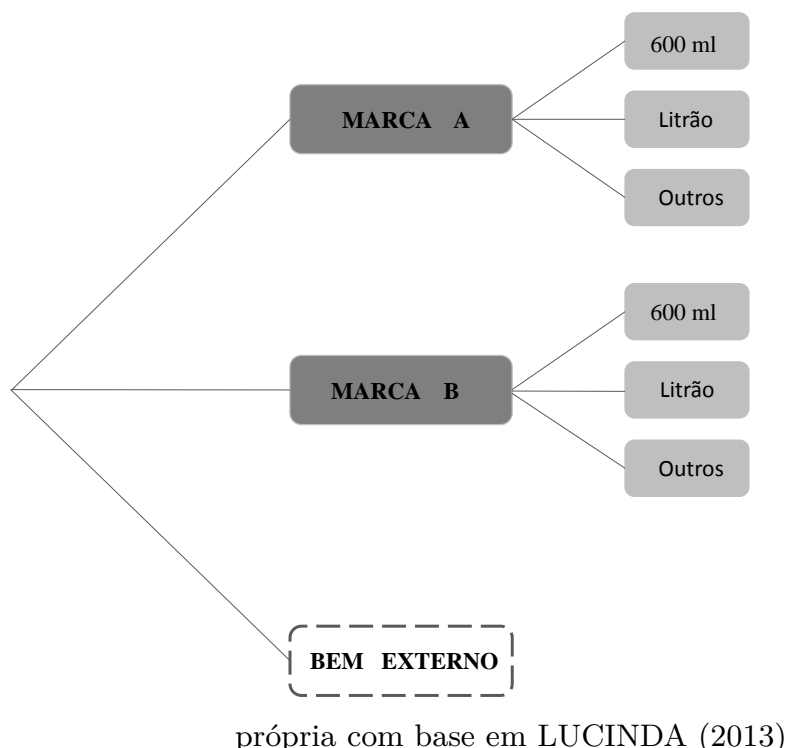

Fonte: Elaboração

quanto $\epsilon_{i j}$ denota a parte aleatória da utilidade.

$$
\ln \left(s_{j}\right)-\ln \left(s_{0}\right)=\alpha p_{j}+\overline{\mathbf{x}_{\mathbf{j}}} \beta_{i j}+(1-\sigma) \ln \left(s_{j \mid k}\right)
$$

Na equação acima, o termo $\ln \left(s_{j \mid k}\right)$ denota a participação do produto j dentro do ninho K em que ele está inserido.

No modelo aninhado, o processo decisório em duas etapas tem a seguinte forma (LUCINDA, 2013):

$$
\ln \left(s_{j}\right)-\ln \left(s_{0}\right)=\mathbf{x}_{\mathbf{j}} \beta_{j}+\left(1-\sigma_{1}\right) \ln \left(s_{j \mid K}\right)+\left(1-\sigma_{2}\right) \ln \left(s_{K \mid L}\right)+\xi_{j}
$$

com $s_{K \mid L}$ denotando a representatividade do nível de ordem inferior sobre o ninho de ordem superior e $\xi_{j}$ capturando as características não observadas dos produtos pelo econometrista, porém de forma distinta do modelo com apenas uma etapa de decisão. A correlação entre o erro econométrico e as características observáveis poderia ser um obstáculo para a estimação do modelo, mas para solucioná-lo, utilizamos variáveis instrumentais. Utilizamos os intrumentos propostos por Berry, Levinsohn \& Pakes (1995), sendo eles: as características dos produtos; a soma das características dos produtos da mesma marca e a soma das características dos produtos das marcas rivais. 


\subsubsection{Efeitos marginais e elasticidades}

A probabilidade de escolha por determinada alternativa no modelo em duas etapas pode ser decomposta em dois fatores, sendo (a) probabilidade de escolha do ninho em que o produto selecionado está inserido e (b) a probabilidade de escolha desse produto, condicional à escolha do ninho:

$$
P_{j}=P_{j \mid K} \times P_{K \mid L} \times P_{L}
$$

Assim, é possível reescrever os efeitos marginais de uma mudança em um atributo x sobre a probabilidade de escolha:

$$
\frac{\partial P_{j}}{\partial x_{r}}=\frac{\partial P_{j \mid K}}{\partial x_{r}} P_{K}+\frac{\partial P_{K}}{\partial x_{r}} P_{j \mid K}
$$

Uma implicação desse modelo é que pode-se encontrar resultados diferentes caso $\mathrm{r}$ for o mesmo produto $\mathrm{j}$, se r e j forem dois produtos diferentes em um mesmo ninho ou se $\mathrm{r}$ e j forem de ninhos diferentes e se os produtos estiverem em ninhos inferiores diferentes em um mesmo ninho superior. Utilizaremos equações específicas para a obtenção das elasticidades, de acordo com os produtos em questão e os ninhos em que se inserem, conforme o autor LUCINDA (2013).

Mesmo produto

$$
\epsilon_{j, p_{j}}=\alpha \frac{p_{j}}{1-\sigma_{1}}\left[1-s_{j \mid K}\left(1-\frac{1-\sigma_{1}}{1-\sigma_{2}}\right)-s_{j \mid L}\left(\frac{\sigma_{2}\left(1-\sigma_{2}\right)}{1-\sigma_{2}}\right)-\left(1-\sigma_{1}\right) s_{j}\right]
$$

Produtos diferentes pertencentes ao mesmo ninho

Para casos em que $r \neq j$, porém façam parte do mesmo ninho inferior, teremos:

$$
\epsilon_{j, x_{r}}=\alpha \frac{p_{j}}{\sigma_{1}}\left[s_{j \mid K}\left(1-\frac{1-\sigma_{1}}{1-\sigma_{2}}\right)-s_{j \mid L}\left(\frac{\sigma_{2}\left(1-\sigma_{2}\right)}{1-\sigma_{2}}\right)-\left(1-\sigma_{1}\right) s_{j}\right]
$$


Produtos diferentes, em ninhos inferiores diferentes, porém no mesmo ninho superior

$$
\epsilon_{j, p_{j}}=\alpha \frac{p_{j}}{\sigma_{1}}\left[-s_{j \mid L}\left(\frac{\sigma_{2}\left(1-\sigma_{2}\right)}{1-\sigma_{2}}\right)-\left(1-\sigma_{1}\right) s_{j}\right]
$$

Essas medidas de sensibilidade às diferentes características dos produtos nos permitem encontrar as elasticidades da demanda própria e preço cruzada.

\subsection{Dados}

A base de dados a ser utilizada neste trabalho é composta por informações sobre preços e vendas de bebidas coletadas pelas sete regiões em que a AC NIELSEN ${ }^{1}$ atua. Essa empresa possui um registro virtual de todos os dados de venda e preços dos principais varejistas e atacadistas.

As informações estão dispostas mensalmente, sendo que o intervalo dos registros vai de outubro de 2007 a dezembro de 2008. Com dados de volume de vendas e receita obte-ve o preço médio por litro e ainda deflacionou-se a receita de acordo com o Índice de Preços ao Consumidor Amplo do IBGE. Os estabelecimentos são desagregados de acordo com a forma que a venda ocorre. Os canais classificados como "Tradicionais" possuem atendimento por vendedores ou balconistas; dentre elas estariam mercearias e padarias, por exemplo. Já os "Auto-Serviços" tratam-se de locais em que não ocorre esta intermediação, mas em que constam caixas registradoras (ex. lojas de conveniência). Já o canal "Bar"reúne lugares em que há consumo local, como lanchonetes e bares. No entanto estão excluídos desse índice locais restaurantes puros, casas noturnas e bares situados em locais fechados como escolas e clubes.

A região I é composta pelos estados do Ceará, Rio Grande do Norte, Paraíba, Pernambuco, Alagoas, Bahia e Sergipe. Já a região II tem como integrantes os estados de Minas Gerais, Espírito Santo e os municípios do interior do Rio de Janeiro (são excluídos os municípios que fazem parte da área III). Na região III, por sua vez, estão contidos os municípios que integram a Grande Rio de Janeiro, sendo eles: Rio de Janeiro, Niterói, Nova Iguaçu, Duque de Caxias, Nilópolis, São Gonçalo e São João de Meriti. De forma semelhante foi agregada a região IV, da qual fazem parte os municípios da Grande São Paulo: São Paulo, Santo André, São Bernardo do Campo, São Caetano do Sul, Diadema,

1 "A Nielsen Company é uma empresa germânico-americana com sede em Nova Iorque, nos Estados Unidos. A empresa oferece uma variedade de informações em pesquisas de mercado, usando metodologias próprias. "Fonte: Wikipedia, 12/01/2015 
Figura 2: Regiões de coleta dos dados

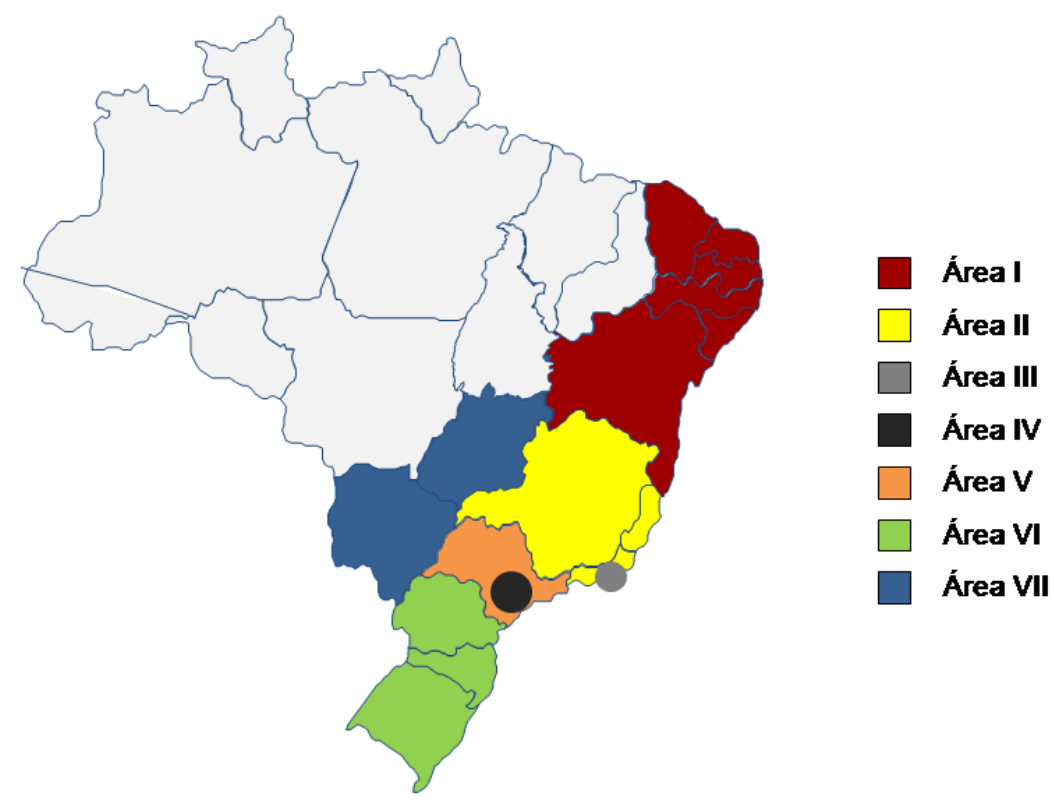

Fonte: Elaboração própria.

Mauá, Guarulhos, Osasco, Embu e Taboão da Serra. Os municípios do interior paulista que não foram citados integram a região V. Os estados sulistas, isto é, Paraná, Santa Catarina e Rio Grande do Sul compõem a região VI e, por fim, Brasília, Mato Grosso do Sul e Goiás estão representados na região VII.

Também foram utilizados dados da Pesquisa de Orçamentos Familiares (POF/20082009) com o intuito de se estimar o mercado potencial de bebidas. A POF é desenvolvida pelo Instituto Brasileiro de Geografia e Estatística e tem os domicílios como unidade de coleta. Nesse sentido, a POF permite ao pesquisador conhecer os hábitos de consumo das famílias pesquisadas.

O cadastro de produtos da POF confere acesso às quantidades consumidas dos produtos pelas famílias brasileiras. Nessa base de dados, a cada item comprado é atribuído um código e uma classificação de grupo de produtos semelhantes. Assim, os alimentos e produtos alimentícios pertencerão a um mesmo grupo, sendo que os líquidos dessa categoria também estarão identificados. Dessa forma, é possivel acessar as bebidas consumidas pelos domicílios com facilidade (ver Apêndice).

Para cada produto cadastrado adquirido pela unidade familiar, tem-se o código de local de aquisição e unidade de medida do bem. Por meio do cruzamento de dados é possível, portanto, conhecer a quantidade comprada na forma de peso ou volume em cada estabelecimento. 
Nesse sentido, para estimarmos o mercado de bebidas total, fizemos duas classificações a partir do "Cadastro de produtos da POF": uma referente aos produtos e outra, aos canais de venda. No que se refere à primeira, selecionamos os alimentos dessa base de dados e classificamo-os manualmente, tomando-se produtos como "sucos", refrigerantes", "cervejas", etc., como bebidas. Em seguida, categorizamos os produtos como alcoólicos e não alcoólicos para, por fim, classificar as bebidas alcoólicas como cervejas ou outros.

Tratando-se da segunda classificação, fazia-se necessário considerar nesse mercado potencial apenas os canais de venda considerados pela Nielsen. Nesse sentido, utilizamos a tabela de "Cadastro de local de aquisição da POF", que contém todos os estabelecimentos declarados pelas famílias como fonte de compra. Tomamos os pontos de venda em que deve ocorrer o comércio de bebidas e selecionamos para a construção do mercado potencial total. Esses canais foram classificados de acordo com a metodologia ACNIELSEN ${ }^{2}$, atribuindo-se a denominação "Tradicional" caso houvesse intermédio de atendente e caixa registradora; "Auto-Serviço" se não se fizesse presente o vendedor pudessem haver caixas registradoras; e "Bar"onde constasse consumo local. Assim como na metodologia utilizada pela ACNIELSEN, foram excluídos restaurantes puros, casas noturnas e bares situados em locais fechados.

Classificamos as Unidades da Federação de acordo com a definição da ACNIELSEN, de modo a estimarmos o mercado total de bebidas na mesma região dos dados ACNIELSEN que dispúnhamos. Desse modo, seriam considerados apenas os domicílios que estão localizados nas regiões geográficas de análise. Por meio da tabela de estratos geográficos foi possível definir o mercado metropolitano, como denotam as áreas III e IV.

Selecionamos o quadro da POF de interesse (de 63 a 69, como mostra o Apêndice) e o número do grupo de despesa referentente e, assim, obtivemos a estimação do mercado potencial.

A partir dos procedimentos supracitados, estimou-se que 79,03\% das bebidas vendidas contém álcool em sua formulação na região I. Se desagregarmos pelos canais de venda, temos que 70,92\% do volume vendido em auto-serviços correspondem a bebidas alcoólicas, contra 71,55\% em estabelecimentos tradicionais e $94,61 \%$ em bares.

Tratando-se da região II, estimou-se que 85,48\% das bebidas consumidas de acordo com a POF são alcoólicas. Essa porcentagem é ainda maior em bares, chegando a 91,43\% do volume comercializado. Para estabelecimentos tradicionais e de auto-serviços, temos $81,49 \%$ e $83,5 \%$, respectivamente.

No caso da região III, a representatividade das bebidas alcoólicas frente ao volume vendido em média é menor. Estimou-se que 64,95\% do volume de bebidas comercializados

2 A ACNIELSEN considera mercearias e padarias como locais tradicionais e, dessa forma, classificamos os estabelecimentos que seriam semelhantes como tais. Essa intuição foi aplicada para todos os tipos de canais. 
nessa área correspondem a produtos que contém álcool etílico. Em bares, essa porcentagem sobe para 96,94\%, enquanto os estabelecimentos tradicionais são responsáveis por apenas $34,77 \%$ do volume vendido. Para auto-serviços, a porcentagem é um pouco mais elevada, chegando a $63,13 \%$.

Referente à região IV, encontrou-se uma média de 77,67\% do volume de bebidas totais vendidas que podem ser classificados como produtos alcoólicos. A maior porcentagem é encontrada em auto-serviços, chegando a 86,25\%, seguida de canais tradicionais com $77,44 \%$ de representatividade. Os bares, por sua vez, têm 69,3\% dos litros de bebidas comercializados correspondentes a bens alcoólicos.

Na região $\mathrm{V}$ foi encontrada a maior participação das bebidas alcoólicas sobre o volume vendido de bebidas, com 90,4\% em média na representatividade das vendas (em volume). A porcentagem é maior em bares, com 96,37\% dos litros vendidos, contra 86,94\% em auto-serviços e $87,88 \%$ em canais tradicionais.

Em média, 76,36\% do volume comercializado de bebidas é composto por bebidas alcoólicas na região VI. Em locais de auto-serviços, esse número sobe para 85,57\%, enquanto encontramos $70,77 \%$ em bares e 73,02\% em canais tradicionais de consumo.

Por fim, temos para a região VII o consumo das famílias de bebidas alcoólicas estimado em $86,54 \%$ do total de líquidos para ingestão. Desagregando por tipos de estabelecimentos, chegamos a $93,44 \%$ em bares, $82,78 \%$ em auto-serviços e $83,38 \%$ em locais tradicionais.

Obtivemos assim, a proporção de consumo de cerveja em volume por região Nielsen e estabelecimento de venda. Trataremos agora do consumo de cervejas por regiões e estabelecimentos no período em torno da aprovação da Lei Seca.

\subsubsection{Resposta da demanda por cervejas à Lei Seca}

Com o endurecimento das penalidades frente aos motoristas alcoolizados, houve o florescimento de dúvidas por parte dos consumidores com relação aos efeitos do álcool no sangue e a possibilidade de dissipação da substância no organismo. Isso porque, se antes havia uma certa tolerância com relação aos níveis de álcool constatados via teste de alcoolemia, com a aprovação da Lei Seca o condutor consumidor de cervejas passou a questionar se era possível desfrutar da bebida e depois abster-se por determinado período de modo que, caso o teste de alcoolemia fosse aplicado, seu resultado não acusasse consumo de álcool. Nesse sentido, os consumidores passaram a questionar se haveria uma quantidade da substância que poderia ser ingerida sem que se pudesse detectar sua presença no sangue ou o tempo de espera entre o consumo e dissipação no organismo (novamente, com a intenção de não ser registrada via teste de alcoolemia). No entanto, para ambas as perguntas não há uma resposta ótima que abranja todos os indivíduos e situações em 
que estão inseridos. Isso porque o tempo de permanência do álcool no sangue varia entre os consumidores, uma vez que está relacionado a sexo, peso, idade, condições de saúde e outros fatores intrínsecos. Isto é, a sensibilidade dos indivíduos frente à ingestão de bebidas alcoólicas é diferente, sendo que o próprio consumidor a desconhece na maior parte das vezes.

Além disso, para uma mesma pessoa, os efeitos do consumo de bebidas alcoólicas serão maiores caso a ingestão são seja acompanhada de alimentos e água. Em jejum, a absorção será mais rápida e o indivíduo perderá mais rapidamente seu senso crítico, coordenação e reflexos. Nesse sentido, devido ao desconhecimento da capacidade de o próprio sangue metabolizar a substância e à insegurança com relação aos resultados da detecção de níveis de alcoolemia no sangue, parte dos indivíduos reduziu seu consumo como resposta imediata à aprovação da Lei Seca.

Os gráficos mostram o comportamento da demanda, deixando clara uma queda do consumo de cervejas após a aprovação da Lei Seca em todas as regiões avaliadas. Há de se admitir que houve uma lenta recuperação após três meses, o que pode ser explicado por alguns fatores como aumento da renda dos consumidores ou reestabelecimento dos níveis anteriores de consumo devido a uma avaliação baixa de risco de ser enquadrado na Lei (o que corresponderia a baixo enforcement). Por isso, ao avaliar-se um intervalo pequeno de variação de quantidade, estamos considerando um intervalo pequeno. Desse modo, é plausível que as quantidades consumidas de cerveja no mês imediatamente anterior e posterior à aprovação da Lei variem devido aos mesmos fatores apenas (excetuando-se a própria Lei).

Nesse sentido, faz-se importante a análise de um imposto equivalente à queda de demanda que sucedeu a aplicação de maiores penalidades aos motoristas alcoolizados. Os efeitos de um aumento de preços seriam mais persistentes sobre a demanda do que a queda localizada no entorno da aprovação da Lei Seca. Isso porque os consumidores respondem a incentivos e, conhecidas suas elasticidades preço-própria e cruzadas no momento em que a Lei foi aprovada, podem ser estimadas suas escolhas a partir de um reajuste de preços. Ao longo da aplicação da Lei, os consumidores criaram mecanismos para burlar as fiscalizações. ${ }^{3}$ Os condutores de veículos passaram a trocar informações sobre a presença de

3 Dentre algumas ferramentas posteriormente difundidas entre os condutores, destacou-se o Twitter, uma rede social que permite que os usuários enviem e recebam atualizações pessoais entre contatos. Criado em 2006 nos Estados Unidos da América, a comunicação por tweets (mensagens de até 140 caracteres) é feita em tempo real via website do serviço, SMS ou softwares específicos de gerenciamento. Em 2009 foi criado o perfil Lei Seca RJ, que em abril de 2015 contava com 924 mil seguidores recebendo informações sobre a presença de policiais fiscalizando condutores. Ao longo desses seis anos, foram disseminadas mais de 408 mil mensagens com conteúdo que auxilia o desvio de rotas dos motoristas alcoolizados. Em 2010 foi criado o perfil Lei Seca SP, que informa aos seus seguidores a localização de fiscais portadores de bafômetros na cidade de São Paulo. Em abril de 2015, tal perfil contava com mais de 23 mil seguidores e superadas 5.069 mensagens difundidas. Esses mecanismos que auxiliam os condutores a burlarem a Lei foram aprimorados, de modo que foram criados inclusive aplicativos para a reunião deles, facilitando a comunicação entre os consumidores de bebidas alcoólicas. 
Figura 3: Demanda por cervejas na Área I

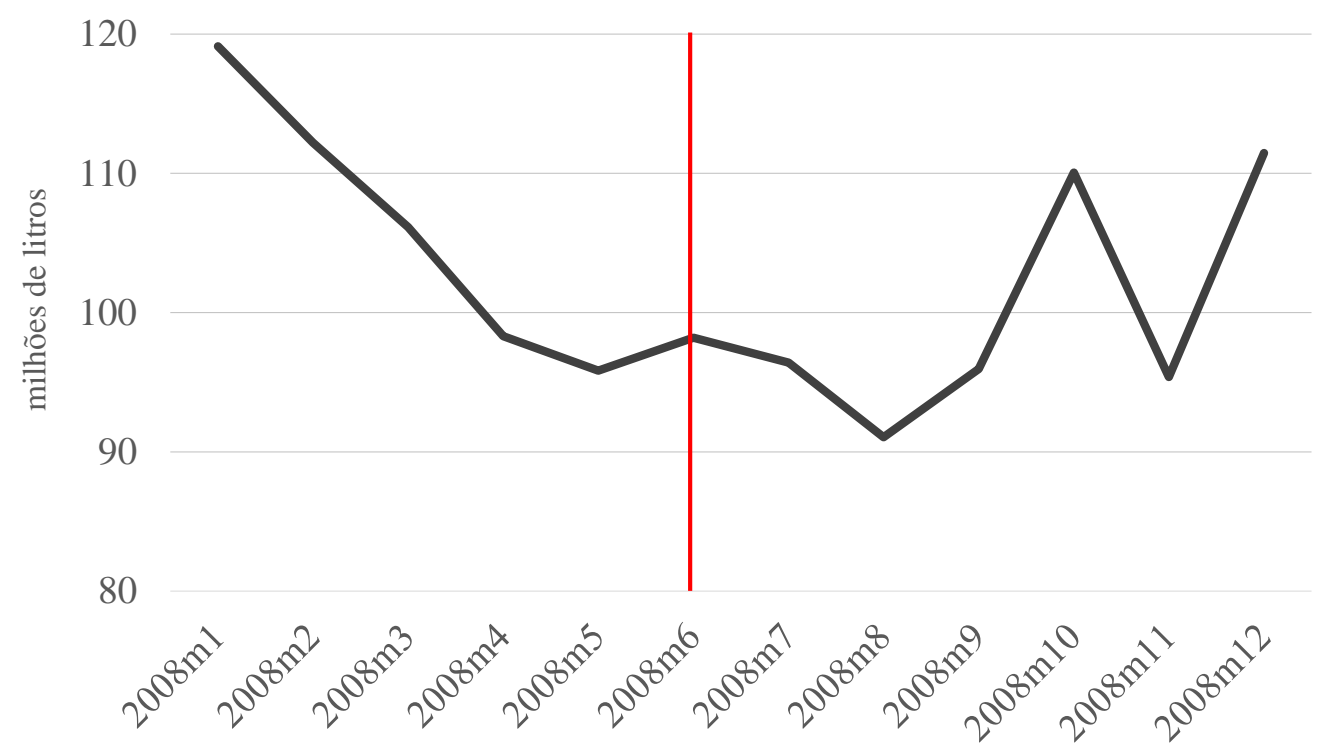

Fonte: Elaboração própria.

blitz policiais, compartilhando suas localizações e incentivando os condutores alcoolizados a mudarem seus trajetos a fim de desviarem-se da fiscalização.

O ajuste dessas ferramentas de comunicação é um fator que contribuiu para o reajuste da demanda, visto que confere uma redução de enforcement para o cumprimento da Lei. Nesse sentido, um imposto equivalente à redução de demanda observada no entorno da Lei, quando os consumidores ainda estavam ajustando seus meios de comunicação (ainda não amplamente difundidos) poderia ter efeitos mais permanentes.

A figura 3 que corresponde à área I mostra uma queda de 98,2 milhões de litros em junho de 2008 para 96,4 milhões de litros no mês imediatamente posterior. Essa redução de 1,8 milhões de litros representa, em termos percentuais, - 1,83\%.

Na região II, por sua vez, verificou-se uma diminuição de 5,5\% no volume de cervejas comercializado, como mostra a figura 4. Em termos absolutos, passou-se de 102,8 milhões de litros para 97,2 milhões de litros comprados, em junho e julho de 2008, respectivamente - totalizando uma queda de 5,6 milhões de litros comercializados.

Em se tratando da região III, o volume absoluto foi reduzido em 2,4 milhões de litros nos dois meses no entorno da aprovação da Lei Seca, como é possível notar na figura 5. Se em junho de 2008 os consumidores da região metropolitana do Rio de Janeiro adquiriam 60,2 milhões de litros de cerveja, no mês seguinte, o consumo se reduziu para 57,8 milhões de litros. Em termos relativos, houve uma queda, portanto, de 4,03\% na venda do produto.

Nota-se na figura 6 que a região metropolitana de São Paulo (área IV) também teve queda no consumo observada no entorno da aprovação e aplicação da Lei Seca. 
Figura 4: Demanda por cervejas na Área II

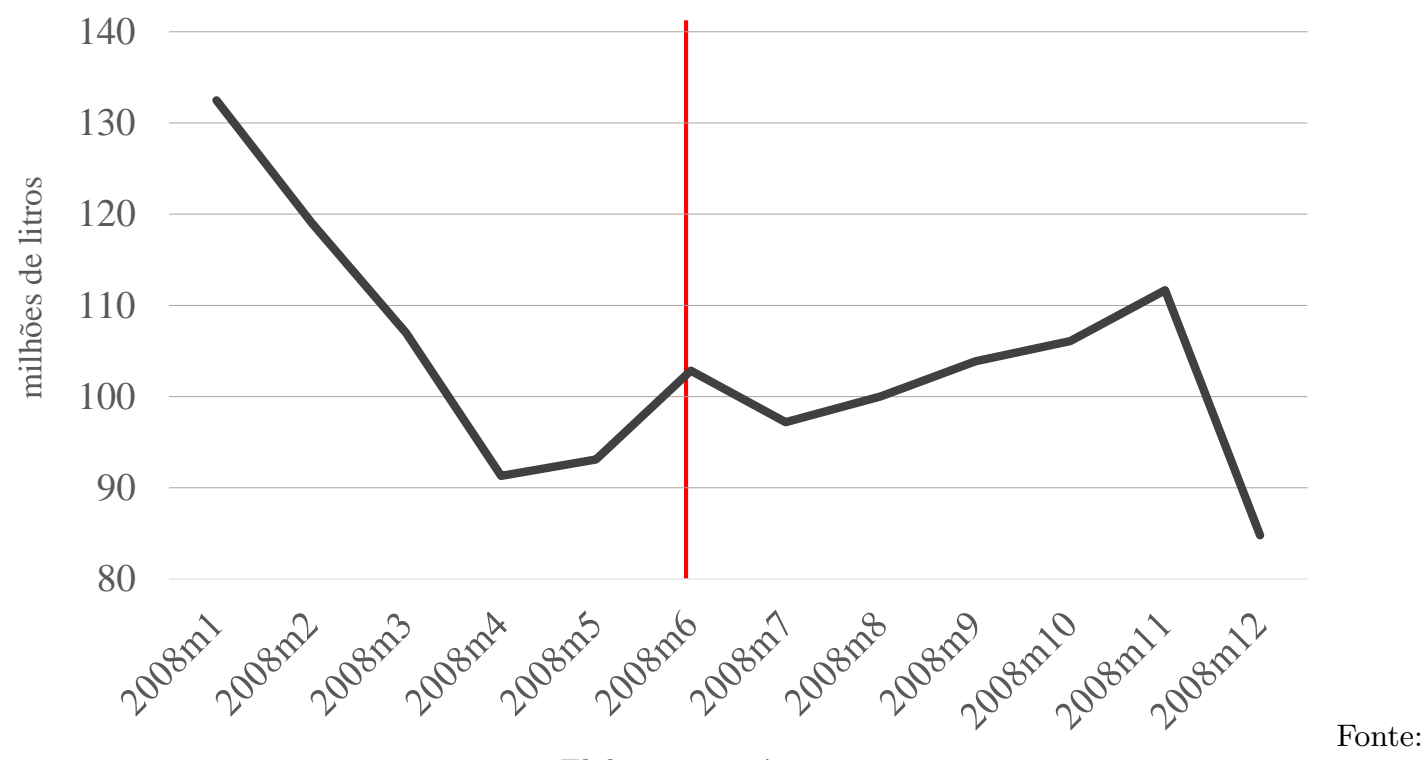

Elaboração própria.

Figura 5: Demanda por cervejas na Área III

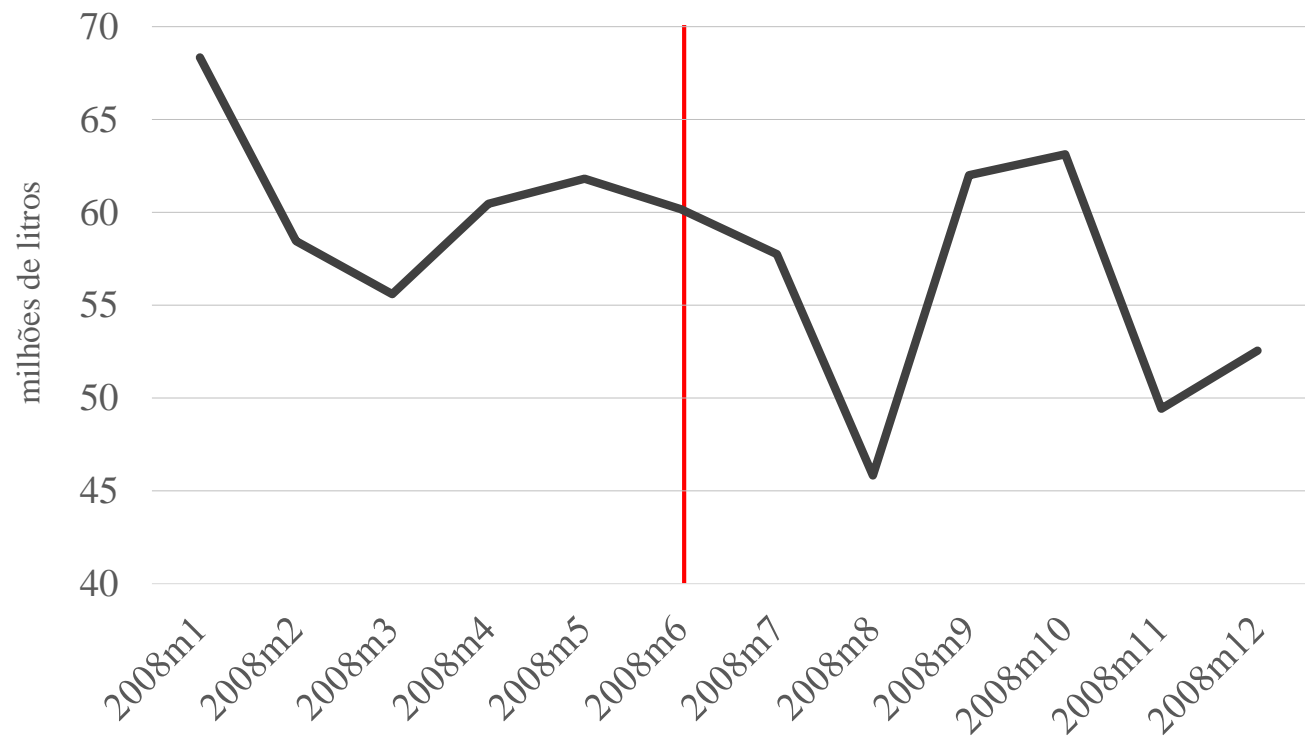

Fonte: Elaboração própria. 
Figura 6: Demanda por cervejas na Área IV

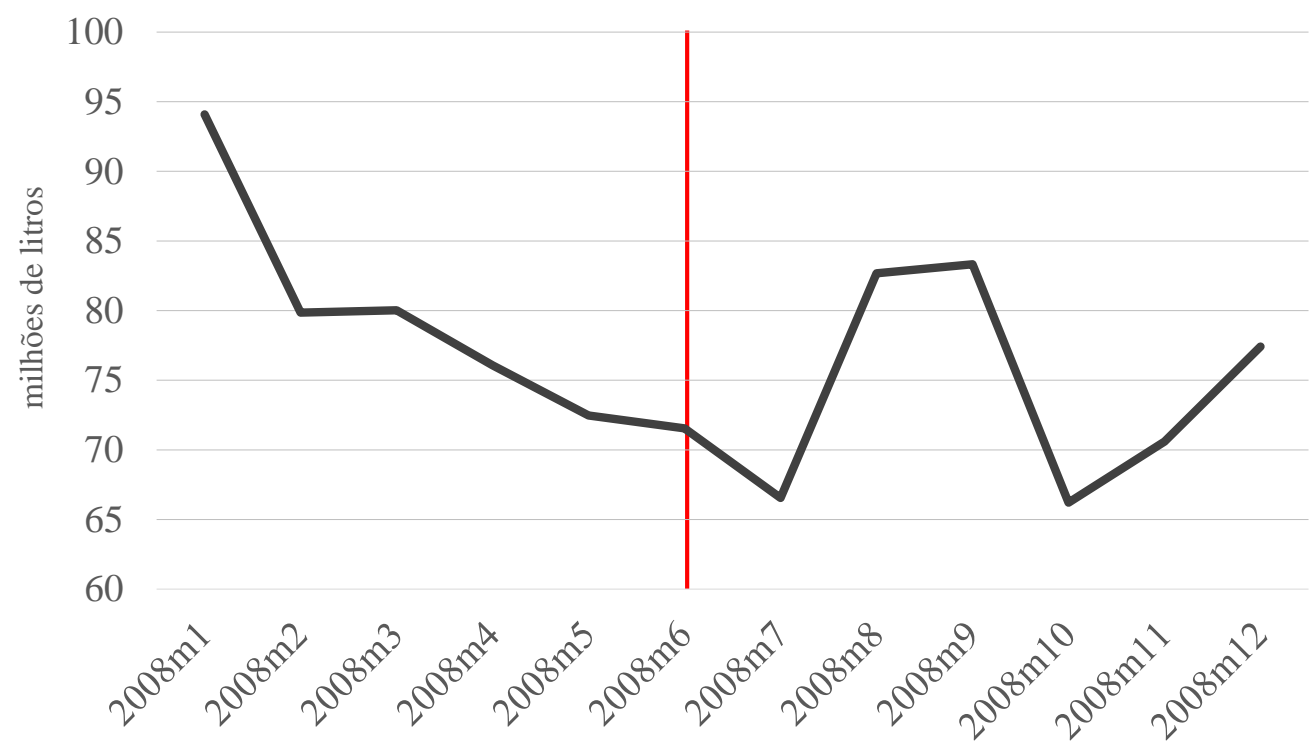

Fonte: Elaboração própria.

Figura 7: Demanda por cervejas na Área V

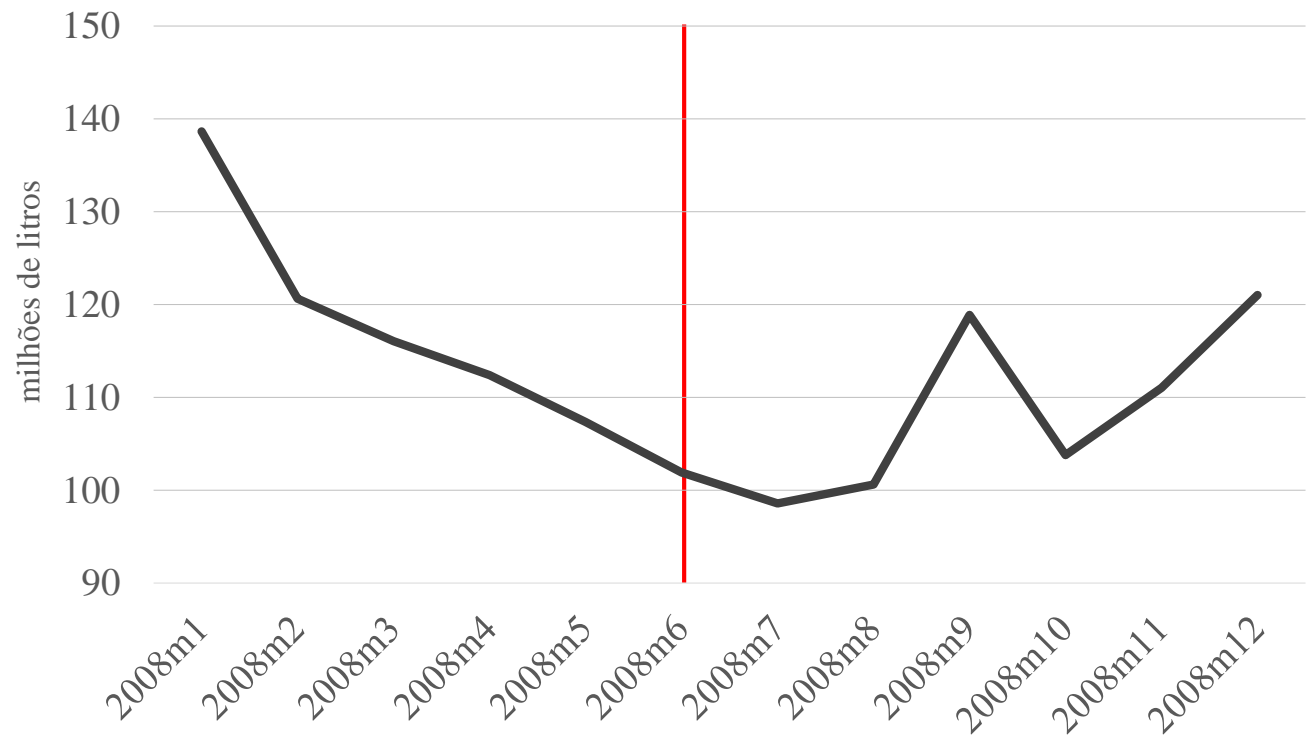

Fonte: Elaboração própria.

Com o endurecimento das penalidades aos condutores alcoolizados, dúvidas com relação à resposta do organismo com relação à absorção do álcool e temor referente às fiscalizações, os consumidores dessa região passaram a comprar 6,99\% menos cervejas. Tratando-se de valores absolutos, em junho de 2008 eram vendidos 71,5 milhões de litros, caindo para 66,5 milhões de litros em julho do mesmo ano - totalizando uma redução de 5 milhões de litros.

No interior do estado, os paulistas também reajustaram o consumo como resposta à referida Lei, como mostra a evolução do consumo na figura 7 . Houve queda de 3,3 milhões de litros em nível, passando-se de 101,9 para 98,6 milhões de litros de cerveja em 
Figura 8: Demanda por cervejas na Área VI

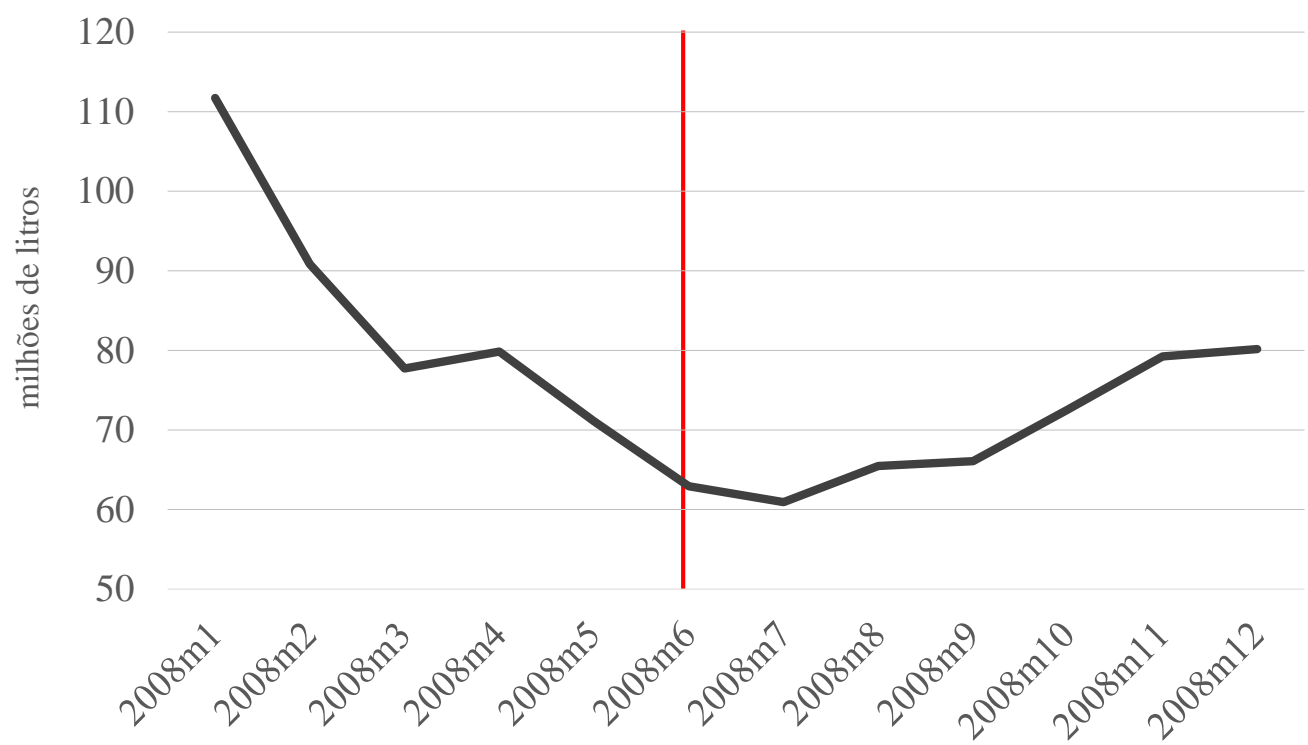

Fonte: Elaboração própria.

Figura 9: Demanda por cervejas na Área VII

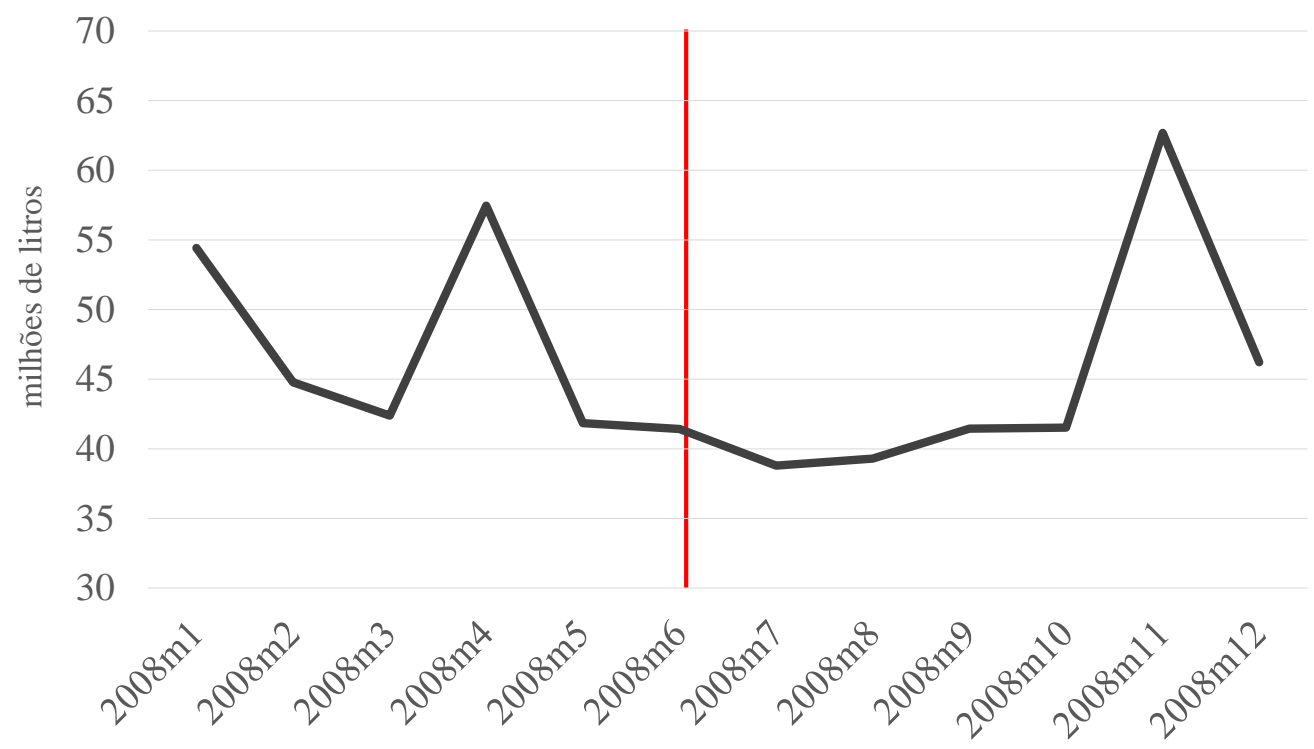

Fonte: Elaboração própria.

apenas um mês. Em termos relativos, esse ajuste dos consumidores tementes à fiscalização via teste de alcoolemia é de $-3,26 \%$.

Os sulistas também reajustaram o consumo de cerveja após a aprovação do enrijecimento das penas aos motoristas infratores. Os consumidores compreendidos pela região VI, deixaram de comprar 2 milhões de litros do produto apenas na passagem de junho para julho de 2008, somando 62,9 e 60,9 milhões de litros, respectivamente. Tal queda significa, em termos relativos, $-3,17 \%$ do volume comercializado, como mostra a figura 8 .

Por último, tratando-se dos consumidores da região VII, foi registrada uma queda 
Figura 10: Representatividade das vendas por tipo de envase no Brasil

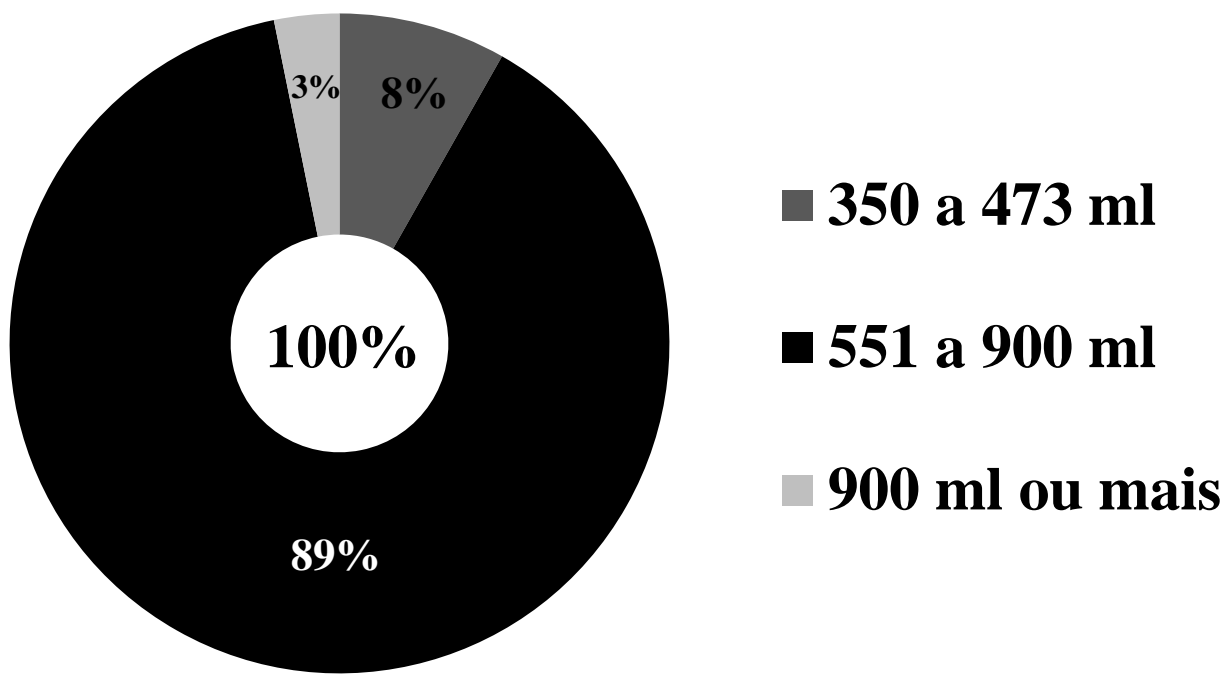

Elaboração própria.

Fonte:

de 41,4 para 38,8 milhões de litros de cerveja vendidos entre junho e julho de 2008. A figura 9 mostra que os pontos de venda localizados no Mato Grosso do Sul e Goiás passaram a vender menos 2,6 milhões de litros em apenas um mês, o que representa uma queda de $6,36 \%$.

No que se refere ao consumo de cervejas de acordo com os envases, notamos uma preferência revelada dos consumidores brasileiros por formatos de 551 a 900 mililitros, como mostra a figura 10. Essas embalagens são responsáveis por cerca de $89 \%$ das vendas no período, em média, totalizando mais de 1,5 bilhão de litros vendidos mensalmente. Em seguida, estão os envases para consumo individual, com aproximadamente $8 \%$ de representatividade do volume comercializado no período. Mensalmente, cerca de 143 milhões de litros de cerveja são vendidos na forma de 350 a 473 mililitros, em média. Com menor alcance estão as embalagens com capacidade superior a $900 \mathrm{ml}$, somando $3 \%$ do consumo no país, o que representa pouco menos de 56 milhões de litros por mês, em média.

Tratando-se das vendas por estabelecimentos, a figura 11 mostra que a maior parte dos brasileiros compra cervejas em bares. Esses locais são caracterizados pela venda do produto pronto para o consumo, uma vez que as bebidas são refrigeradas no próprio estabelecimento. Aproximadamente $62 \%$ do volume comercializado ocorre em bares, ou $66 \%$ da receita. Em termos absolutos, isso significa que os brasileiros consumiram quase 526 milhões de litros de cerveja em bares por mês em média, movimentando pouco mais de 2,3 bilhões de reais apenas nesses estabalecimentos a partir da compra dessa bebida ao mês. Em seguida estão os estabelecimentos tradicionais, isto e, aqueles em que há intermédio de um vendedor. Esses locais são responsáveis por $25 \%$ do volume de vendas ou 210 milhões de litros de cerveja ao mês, em média. A receita mensal nos estebelecimentos 
Figura 11: Representatividade das vendas por estabelecimento no Brasil

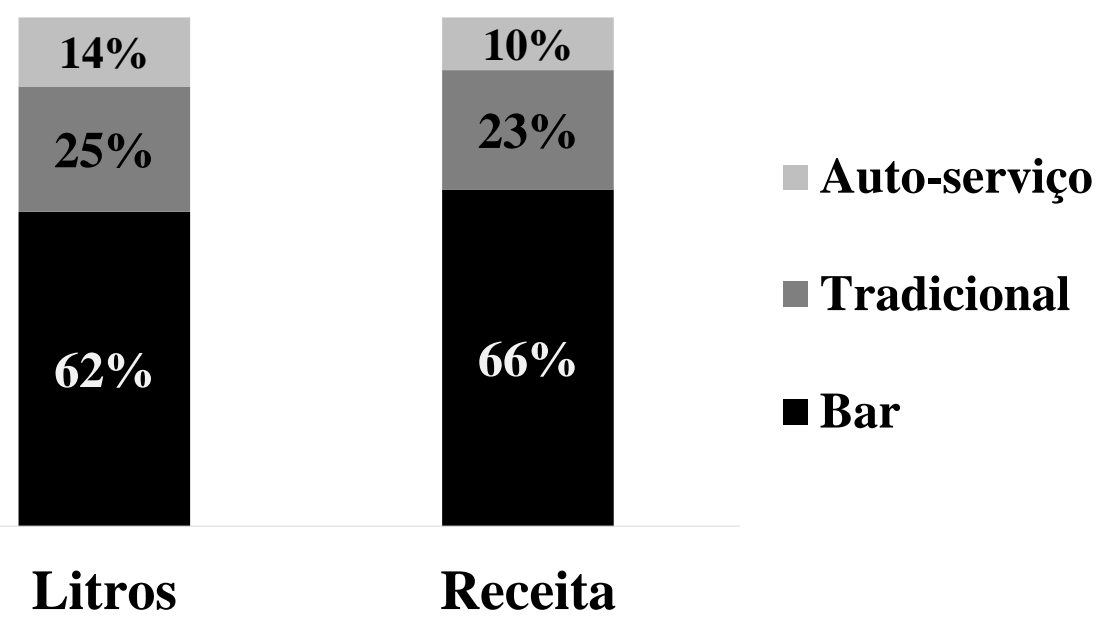

Fonte: Elaboração própria.

tradicionais soma cerca de $23 \%$ do total comercializado no mercado cervejeiro, movimentando aproximadamente 825 milhões de reais. Por último estão os estabelecimentos de auto-serviços, caracterizados pela maior autonomia do consumidor. São neles que $14 \%$ do total vendido em cervejas são comercializados, representando $10 \%$ da receita no setor. Esses valores representam, em termos absolutos, pouco mais de 115 milhões de litros e 363 milhões de reais vendidos por mês, em média no período.

Referente às embalagens de $551 \mathrm{ml}$ a $900 \mathrm{ml}$, que compõem aproximadamente $89 \%$ das cervejas vendidas ao longo do período em território nacional, analisaremos qual o impacto da Lei Seca de acordo com os pontos de venda. Notamos que houve uma queda no consumo em todos os tipos de estabelecimento no território nacional. No que se refere aos locais de auto-serviço, a figura 13 mostra que no entorno da Lei Seca o consumo diminuiu em cerca de 1 milhão de litros em um mês. Em julho de 2008, um mês após a implementação da Lei, esses estabelecimentos atingiram o menor valor considerando-se os meses anteriores, chegando a 30 milhões de litros de cerveja vendidos na forma 551 a $900 \mathrm{ml}$. Ou seja, em um mês houve queda no consumo de 3,2\%. Tratando-se dos pontos de venda considerados tradicionais, isto é, com vendedores intermediando a venda, houve uma queda substancial no consumo também, como mostra a figura 12 . O volume de litros comercializados caiu de aproximadamente 93 milhões de litros para valores abaixo de 90 milhões em apenas um mês (o que representa uma redução de 3,2\%) Destaca-se o comportamento do consumo em bares, cuja redução foi ainda mais acentuada, apresentada na figura 14. Esses estabelecimentos são caracterizados pela disponibilização de bebidas geladas, próprias para o consumo local. Nesse caso, no mês de junho de 2008 o volume vendido atingia 235 milhões de litros, caindo para 220 milhões em apenas um mês (representando uma queda de 6,4\%). 
Figura 12: Volume vendido no Brasil na forma de garrafas convencionais em estabelecimentos tradicionais

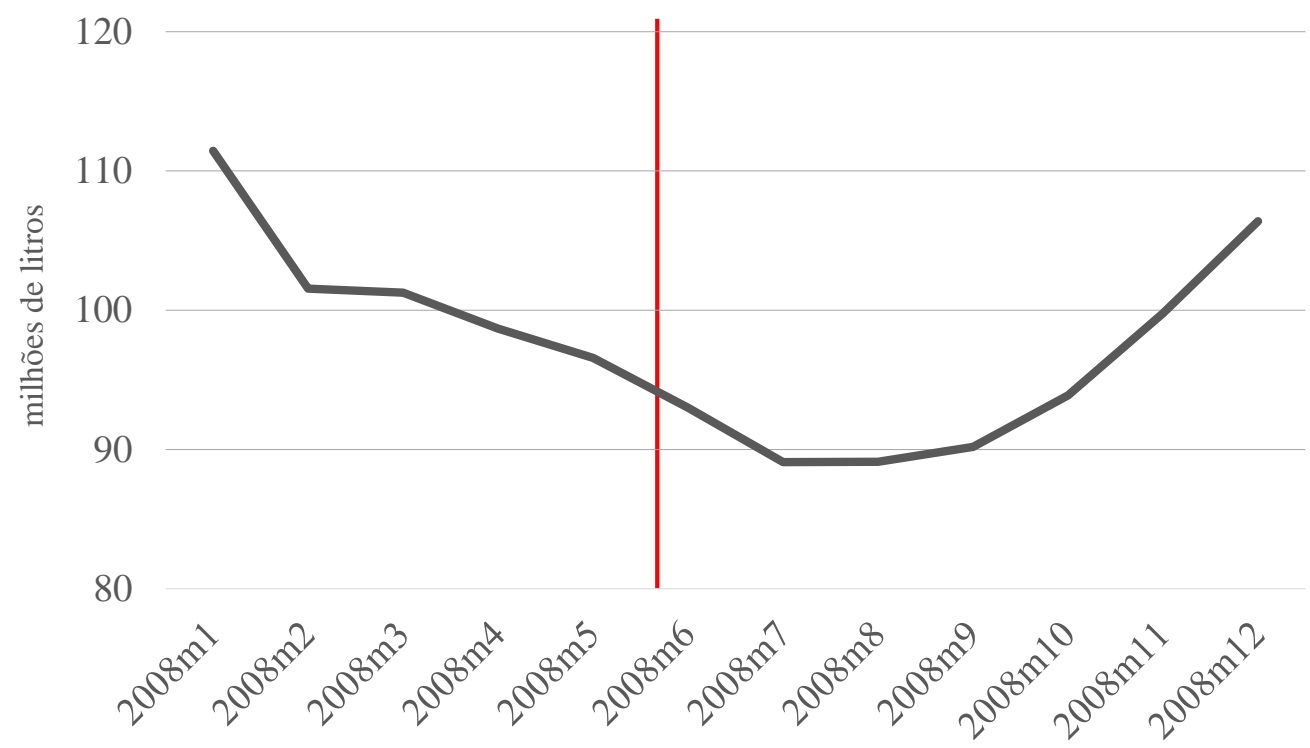

Fonte: Elaboração própria.

Figura 13: Volume vendido no Brasil na forma de garrafas convencionais em estabelecimentos de auto-serviço

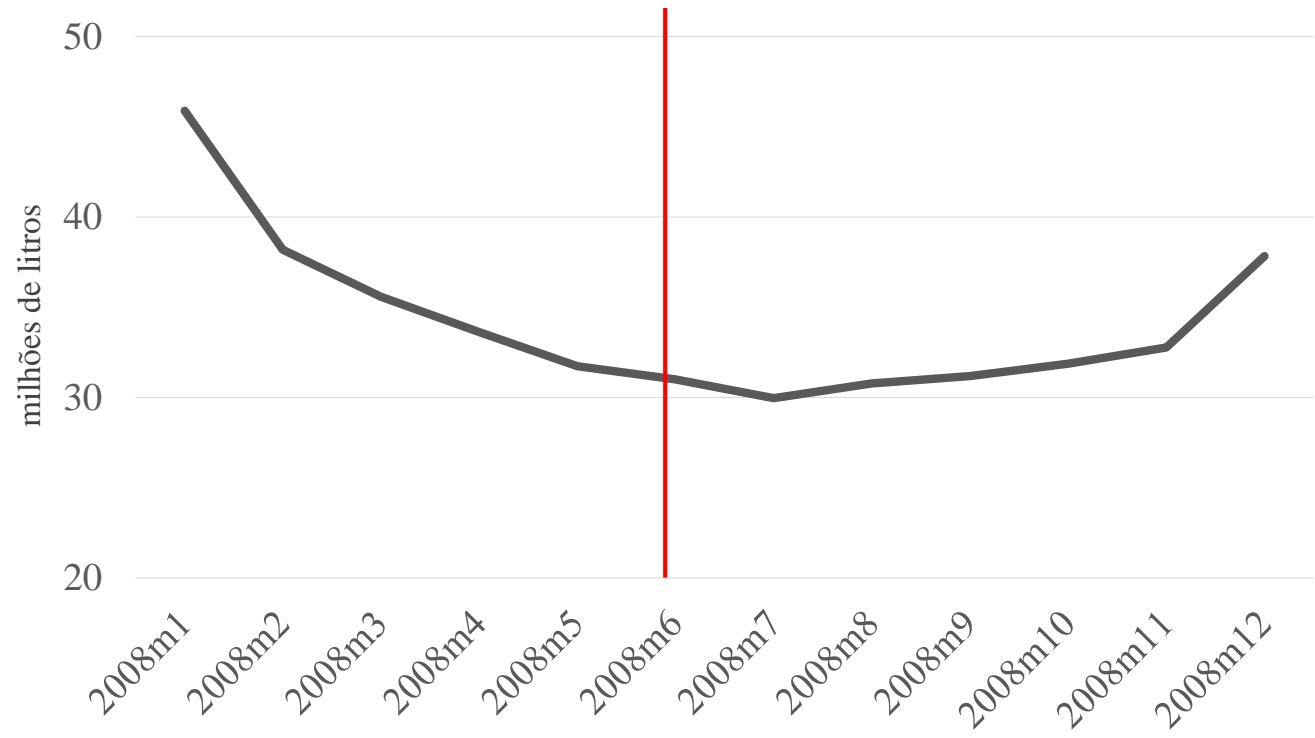

Fonte: Elaboração própria. 
Figura 14: Volume vendido no Brasil na forma de garrafas convencionais em bares

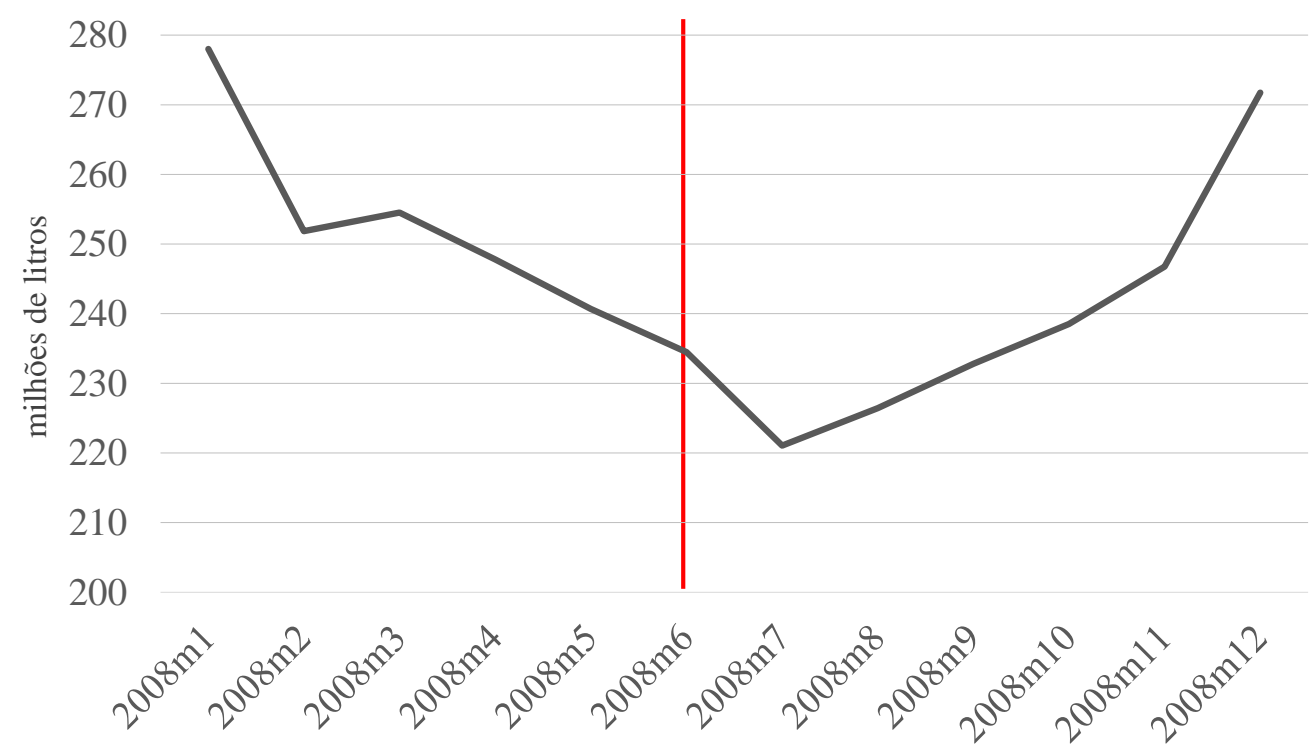

Fonte: Elaboração própria.

Em suma, a aprovação da Lei Federal 11.705 refletiu-se na queda do consumo dos indivíduos em todas as áreas do Brasil estudadas. Nesse sentido, a seção a seguir mostra como seria possivel calcular um imposto equivalente sobre o preço.

\subsubsection{Imposto sobre bebidas}

Existem políticas públicas alternativas para minimizar ou prevenir problemas relacionados ao consumo de álcool. Dentre elas, pode-se restringir o consumo de álcool por menores de idade, alocar recursos para ações preventivas ou de tratamento, aumento do preço das bebidas com essa substância, regulação da promoção do álcool, estratégias educacionais etc. ( Edwards e col., 1994; Babor e col., 2004; Laranjeira e Romano, 2004). De acordo com o levantamento da SENAD (2007), a população brasileira apoia a adoção de novas políticas públicas com objetivo de regular o mercado do álcool. Registrou-se que $56 \%$ da população adulta defende o aumento dos impostos sobre bebidas alcoólicas. O estudo acrescenta ainda que estudos internacionais mostraram que o aumento das taxas sobre esses produtos e seus preços resultaram em uma diminuição do consumo e, mais além, levaram a uma redução dos problemas associados à substância.

Dessa forma, o presente estudo apresentará um imposto com efeitos equivalentes à resposta do consumidor à Lei Seca. Sabendo que a variação da quantidade demandada é igual à transposição da multiplicação da matriz de elasticidades pelo vetor transposto da variação de preços, isto é,

$$
\Delta Q=\left(E . \Delta P^{\prime}\right)^{\prime}
$$


sendo $\Delta Q=\ln \left(Q_{\text {depois }}\right)-\ln \left(Q_{\text {antes }}\right)$ e $\Delta P=\ln \left(P_{\text {depois }}\right)-\ln \left(P_{\text {antes }}\right)$.

Aplicando-se propriedades matriciais:

$$
\begin{gathered}
\Delta Q=\Delta P^{\prime \prime} . E^{\prime} \\
\Delta Q=\Delta P . E^{\prime} \\
\left(E^{\prime}\right)^{-1} \cdot \Delta Q=\Delta P
\end{gathered}
$$

Os resultados dessa simulação para cada região e todas elas reunidas são mostrados na seção seguinte, para cada região e a nível nacional. 


\section{Resultados}

Tabela 1: Resultados do Modelo

\begin{tabular}{lll}
\hline & Modelo 1 & \\
\hline $\mathrm{p}$ & $-0,099$ & $* * *$ \\
& $(-3,49)$ & \\
$\ln \left(\mathrm{s}_{j \mid K}\right)$ & 0,916 & $* * *$ \\
& $(58,69)$ & \\
$\ln \left(\mathrm{s}_{K \mid L}\right)$ & 0,944 & $* * *$ \\
& $(192,20)$ & \\
Tamanho & 0,000 & $* * *$ \\
& $(3,70)$ & \\
\hline Dummy Marca & Sim & \\
Dummy Região & Sim & \\
Dummy Tempo & Sim & \\
Dummy Tipo de Embalagem & Sim & \\
N & 20291 & \\
R2 & 0,803 & \\
Estatística F do primeiro estágio & 141,733 & \\
\hline
\end{tabular}

Elaboração do Autor;Efeitos Marginais; Estatísticas t em Parênteses; ${ }^{*} \mathrm{p}<0,05 ;{ }^{* *} \mathrm{p}<0,01 ;{ }^{* * *} \mathrm{p}<0,001$.

Os resultados da estimação mostram um bom poder explicativo do modelo, uma vez que o $R^{2}=80 \%$ pode ser considerado alto. Além disso, os instrumentos utilizados preços de outras embalagens da mesma marca, preços das mesmas embalagens de outras marcas e número de produtos em cada marca - auxiliaram na identificação dos coeficientes. Isso pode ser visto por meio do teste $\mathrm{F}$, pelo qual rejeitamos a hipótese nula de as variáveis instrumentais serem juntamente iguais a zero.

A variável preço apresenta sinal negativo, como esperado pela intuição econômica. Isto é, a elevação do valor de cada unidade à venda tem efeito negativo sobre a demanda. A literatura define os bens cuja quantidade vendida decai caso o preço aumente como bens normais, como é o caso das cervejas nesse modelo. Utilizamos variáveis binárias temporais como meio de controlar os efeitos de cada mês sobre a demanda, que podem oferecer certa sazonalidade. As dummies de região estão presentes para diferencias os efeitos específicos de cada área estudada sobre a demanda. Isso porque, uma vez que a ACNIELSEN fez a divisão dessas regiões, é de se esperar que elas tenham características semelhantes 
com respeito ao comportamento dos consumidores. Ademais, as variáveis binárias de região também oferecem um controle sobre caracteírticas geográficas que poderiam afetar a demanda.

As dummies de marca e tipo de embalagem (lata, long neck, retornável) também auxiliam a estimação do modelo. A primeira, diz respeito a quanto a demanda pode variar com a presença ou não de determinada marca. Essa variação é distinta entre as marcas, uma vez que algumas possuem mais poder do que outras. Já a segunda, insere no modelo uma possível preferência dos consumidores por determinado tipo de envase. Alguns consumidores podem considerar que embalagens de vidro ofereceriam cerveja de melhor qualidade ou que as latas são mais práticas para o consumo. Nesse sentido, a dummy de tipo de embalagem oferece um controle sobre o comportamento da demanda, enriquecendo o modelo.

A variável binária que capta a influência do tamanho das embalagens vendidas apresentou coeficiente nulo. Dessa forma, a quantidade em litros de cerveja comercializada não é influenciada pelo tamanho do envase.

Os coeficientes de cada participação de mercado, por sua vez, indicam probabilidades de escolha e portanto devem estar entre 0 e 1 . Nota-se que essa condição foi respeitada no modelo, sendo que a probabilidade de escolha de determinado envase uma vez que determinada marca foi escolhida é de $91,6 \%$. Já a probabilidade de escolha de determinada marca entre todos os ninhos de marcas existentes é de 94,4\%. Ambos os coeficientes são significativos e, uma vez que foram utilizados para o cálculo das elasticidades conforme mostrado na seção de metodologia, as elasticidades serão estatisticamente diferentes de zero mostradas a seguir. 


\subsection{Elasticidades}

Tabela 2: Elasticidades para Brasil- junho de 2008

\begin{tabular}{|c|c|c|c|c|c|c|c|c|c|}
\hline & $\begin{array}{c}\text { ANTARCTICA } \\
600 \mathrm{ml}\end{array}$ & $\begin{array}{l}\text { BRAHMA } \\
600 \mathrm{ml}\end{array}$ & $\begin{array}{c}\text { SCHIN } \\
600 \mathrm{ml}\end{array}$ & $\begin{array}{l}\text { SCHIN } \\
\text { outros }\end{array}$ & $\begin{array}{l}\mathrm{SKOL} \\
600 \mathrm{ml}\end{array}$ & $\begin{array}{c}\text { OUTRAS } \\
600 \mathrm{ml}\end{array}$ & $\begin{array}{l}\text { OUTRAS } \\
\text { outros }\end{array}$ & $\begin{array}{c}\text { KAISER } \\
600 \mathrm{ml}\end{array}$ & $\begin{array}{l}\text { ITAIPAVA } \\
\quad 600 \mathrm{ml}\end{array}$ \\
\hline ANTARCTICA_600ml & $-7,1926$ & 1,2782 & 0,8648 & 0,0023 & 0,4407 & 0,8139 & 0,1198 & 0,9244 & 1,0387 \\
\hline BRAHMA_600ml & 0,8519 & $-7,6142$ & 0,8648 & 0,0023 & 0,4407 & 0,8139 & 0,1198 & 0,9244 & 1,0387 \\
\hline SCHIN_600ml & 0,8519 & 1,2782 & $-6,8344$ & 0,0023 & 0,4407 & 0,8139 & 0,1198 & 0,9244 & 1,0387 \\
\hline SCHIN_outros & 0,0131 & 0,0307 & 0,0054 & $-6,5180$ & 0,0183 & 0,0250 & 0,2231 & 0,0031 & 0,0096 \\
\hline SKOL_600ml & 0,8519 & 1,2782 & 0,8648 & 0,0023 & $-7,9863$ & 0,8139 & 0,1198 & 0,9244 & 1,0387 \\
\hline OUTRAS_600ml & 0,8119 & 1,2188 & 0,8238 & 0,0414 & 0,4206 & $-7,1896$ & 0,1425 & 0,8805 & 0,9897 \\
\hline OUTRAS_outros & 0,1099 & 0,1746 & 0,1045 & 0,2550 & 0,0671 & 0,1116 & $-6,9971$ & 0,1094 & 0,1283 \\
\hline KAISER_600ml & 0,8519 & 1,2782 & 0,8648 & 0,0023 & 0,4407 & 0,8139 & 0,1198 & $-7,1911$ & 1,0387 \\
\hline ITAIPAVA_600ml & 0,8519 & 1,2782 & 0,8648 & 0,0023 & 0,4407 & 0,8139 & 0,1198 & 0,9244 & $-7,5071$ \\
\hline
\end{tabular}


As elasticidades da demanda possuem sinais esperados conforme a literatura econômica. Sendo as cervejas bens considerados normais, a quantidade de cada produto deve variar no sentido contrário à elevação de seu próprio preço. Isto é, se o preço da marca Antarctica para as garrafas de $600 \mathrm{ml}$ aumenta, espera-se que o volume comercializado desse produto caia. Esse fato foi observado na tabela de elasticidades, em que Antarctica $600 \mathrm{ml}$ possui elasticidade própria igual a $-7,19$.

Uma vez que os preços e quantidades estão em nível, interpreta-se a elasticidade própria como a variação porcentual das vendas do produto da coluna da tabela 2 referente ao aumento $1 \%$ nos preços do produto da primeira linha. Nesse sentido, a elasticidade própria de Antarctica $600 \mathrm{ml}$ indica que o aumento de uma unidade no próprio preço faz com que sua demanda caia em 7,19\%. Nota-se que todas as elasticidades preço-própria possuem sinal negativo, como mostra a diagonal principal da tabela 2. Sendo assim, todas as combinações de marcas e envases enfrentarão queda no volume comercializado caso o proprio preço aumente.

No entanto, o aumento do preço do próprio produto não significa que os consumidores deixarão de consumir cervejas. Existe uma substituibilidade entre os bens, como mostra a elasticidade preço-cruzada. Nesse caso, o sinal esperado é negativo, de forma que se o preço da Antarctica 600ml aumentar, o consumidor passará a comprar Brahma $600 \mathrm{ml}$ ou outras marcas e envases. A tabela 2 mostra que a quantidade de Brahma $600 \mathrm{ml}$ aumenta em 0,85\% frente o aumento de $1 \%$ no preço de Antarctica $600 \mathrm{ml}$.

Nota-se que as elasticidades cruzadas não são simétricas, isto é, a substituibilidade do produto Brahma 600ml frente a um aumento de preços da Antartica 600ml difere da substituibilidade do produto Antarctica $600 \mathrm{ml}$ frente ao aumento de preços da Brahma 600ml. Isso se deve às probabilidades de escolha obtidas de acordo com a estrutura de ninhos. Uma vez que o consumidor optou pela marca Brahma, a probabilidade de escolha entre cada tipo de envase será diferente da probabilidade da escolha de embalagem condicional à opção pela marca Antarctica. Então, quando consideramos a substituibilidade entre esses produtos com mesmo envase em comum, teremos elasticidades cruzadas distintas. 
Tanto as elasticidades própria como as elasticidades preço-cruzada serão utilizadas para o cálculo de imposto equivalente aos efeitos da aprovação da Lei Seca.

\subsection{Simulação}

Tabela 3: Resultados da simulação de imposto equivalente

\begin{tabular}{|c|c|c|c|c|c|c|c|c|}
\hline & \multicolumn{8}{|c|}{ Variação da Demanda por Região } \\
\hline & $\mathrm{I}$ & II & III & IV & $\mathrm{V}$ & VI & VII & Brasil \\
\hline ANTARCTICA_600ml & $-9,38 \%$ & $-3,70 \%$ & $-3,38 \%$ & $-4,85 \%$ & $-1,88 \%$ & $-4,51 \%$ & $-7,65 \%$ & $-4,78 \%$ \\
\hline BRAHMA_600ml & $-4,60 \%$ & $-8,41 \%$ & $-2,28 \%$ & $-9,29 \%$ & $-6,53 \%$ & $1,60 \%$ & $-12,36 \%$ & $-6,47 \%$ \\
\hline BRAHMA_litrão & - & - & - & - & - & $43,75 \%$ & - & $43,75 \%$ \\
\hline SCHIN_600ml & $-4,13 \%$ & $-3,97 \%$ & $-3,34 \%$ & $-4,97 \%$ & $19,41 \%$ & $-4,21 \%$ & $-3,10 \%$ & $-2,21 \%$ \\
\hline SCHIN_outros & $17,35 \%$ & - & $-10,48 \%$ & $11,23 \%$ & $-1,02 \%$ & $0,29 \%$ & $-10,01 \%$ & $4,99 \%$ \\
\hline SKOL_600ml & - & $-5,15 \%$ & $-2,38 \%$ & $-9,25 \%$ & $-8,69 \%$ & $-2,96 \%$ & $-8,95 \%$ & $-5,92 \%$ \\
\hline KAISER_600ml & $-2,85 \%$ & $0,59 \%$ & - & $-2,36 \%$ & $-4,19 \%$ & $-4,25 \%$ & $1,79 \%$ & $-2,65 \%$ \\
\hline ITAIPAVA_600ml & - & $-6,59 \%$ & $-4,75 \%$ & $-3,41 \%$ & $5,95 \%$ & $16,67 \%$ & $18,34 \%$ & $-4,37 \%$ \\
\hline OUTRAS_600ml & - & $-8,64 \%$ & $-5,43 \%$ & $-14,81 \%$ & $-4,15 \%$ & $-0,35 \%$ & $-0,32 \%$ & $-5,2 \%$ \\
\hline OUTRAS_litrão & - & - & - & - & $-89,80 \%$ & $-50,00 \%$ & $-4,25 \%$ & $-88,24 \%$ \\
\hline OUTRAS_outros & $5,75 \%$ & $-4,07 \%$ & $-5,87 \%$ & $-6,02 \%$ & $-2,02 \%$ & $-4,68 \%$ & - & $-3,29 \%$ \\
\hline$\Delta Q m e ́ d i o$ & $-1,83 \%$ & $-5,50 \%$ & $-4,03 \%$ & $-6,99 \%$ & $-3,26 \%$ & $-3,17 \%$ & $-6,36 \%$ & $-4,56 \%$ \\
\hline Imposto equivalente & $0,55 \%$ & $14,52 \%$ & $15,95 \%$ & $13,58 \%$ & $3,44 \%$ & $3,74 \%$ & $17,84 \%$ & $14,16 \%$ \\
\hline
\end{tabular}

Considerando-se a variação na quantidade de cada produto e as elasticidades própria e preço-cruzada, calculamos um imposto equivalente para todos os produtos. Isto é, calculando-se a variação média na quantidade vendida para cada região e para a reunião de todas as regiões, obtivemos um valor que poderia ser adicionado aos preços resultando numa queda do volume de cervejas comercializado da mesma magnitude que aquele observado em decorrência da Lei Seca. Caso os preços de todos os produtos aumentassem na proporção equivalente calculada, esperaria-se que mesmo havendo uma substituição entre marcas e envases, a média de consumo cairia.

Para obtenção desse valor, primeiro simulamos uma variação de quantidades a partir de uma determinada elevação de preços. Isto é, multiplicando a matriz de elasticidades inversa transposta por um vetor coluna de variação de preços arbitrariamente definido, chegou-se a um vetor coluna de variação de quantidades prevista. Em seguida, calculamos a média da variação de volume vendido desse vetor coluna. Então, estabeleceu-se como restrição que a variação média prevista deveria ser igual à variação média observada e permitiu-se o cálculo de variações de preços do vetor coluna, que havia sido estabelecido 
arbitrariamente a princípio.

A simulação de impostos mostra que a queda nacional de 4,56\% na quantidade total de cervejas demandadas seria equivalente a um aumento de preços de $14,2 \%$. Em simulações, isso significa que a variação na quantidade prevista iguala-se à variação na quantidade observada quando é inserido um imposto de $14,2 \%$

Desagredando por regiões, resultados mostram que o imposto equivalente simulado possui bastante variação. A região I apresentou o menor imposto equivalente dentre todas as áreas estudadas; com um aumento de preços de 0,55\% chegaria-se à variação de litros de cerveja vendidos em decorrência da aprovação da Lei Seca (-1,83\% em média).

Seguindo esta ordem crescente, temos a região V com imposto equivalente de 3,44\% e a região VI, com 3,74\%. Essas regiões apresentaram queda na quantidade demandada em $3,26 \%$ e $3,17 \%$, respectivamente. Nesse sentido, aumentando-se o preço de todas as marcas na proporção mostrada pelo imposto equivalente, chegaria-se à mesma queda no consumo calculada em decorrência da aprovação da Lei Seca.

Para a região II, obteria-se queda na quantidade média demandada da mesma magnitude daquela observada como resultado das maiores penalidades caso passasse a ser cobrado um imposto de 14,52\% sobre o preço. Tratando-se das regiões IV e III, calculouse uma variação de preços de 13,58\% e 15,95\%, respectivamente. Aumentando-se o preço nessa proporção para cada região, esperaria-se uma queda de 6,99\% na área IV e 4,03\% na área III em média. A região VII, por sua vez, apresentou um imposto equivalente de $17,84 \%$ sobre os preços para a queda de $6,36 \%$ no volume comprado médio. 


\section{Conclusão}

O presente estudo trouxe à luz a problemática sobre o consumo de bebidas alcoólicas no Brasil, em especial as cervejas, produto etílico preferido pelos brasileiros. A ingestão dessas bebidas confere um importante problema de saúde pública no Brasil, dada sua iniciação cada vez mais precoce, possibilidade de dependência que o álcool possui e externalidades negativas causadas à sociedade. Essa dissertação tratou especificamente dos efeitos causados pelo enrijecimento das penalidades aos condutores de veículos automotivos alcoolizados, que alteraram o Código de Trânsito Brasileiro em 2008 por meio da Lei n 11.705 .

A adoção dessa medida fundamentou-se em dados da Associação Brasileira de Medicina de Tráfego (Abramet), que reconhecia a ingestão de bebidas alcoólicas como responsável por 30\% dos acidentes de trânsito. Ainda mais, de acordo com o Ministério da Saúde, metade das mortes no trânsito estariam relacionadas ao uso de álcool por motoristas. Nesse sentido, a Lei Seca foi aprovada com o intuito de responsabilizar o infrator sobre os efeitos negativos de suas ações para a sociedade. Sabendo que as pessoas reagem a incentivos, fazer com que o transgressor arque com custos referentes às externalidades negativas por ele causadas é uma forma de inibir o mau comportamento.

Uma das alternativas mencionadas na literatura para enfrentar os problemas causados pela ingestão de bebidas alcoólicas seguida da condução de veículos automotores é o aumento de preços via impostos. O presente trabalho buscou simular uma variação de preços que traria uma queda equivalente à proporcionada pela aprovação da Lei Seca na demanda por cervejas. Segundo o I Levantamento Nacional sobre os Padrões de Consumo de Álcool na População Brasileira (SENAD, 2007), trata-se da bebida alcoólica mais consumida pelos brasileiros, representando $61 \%$ das vendas.

Ademais, de acordo com o estudo da SENAD, o consumo por cervejas representa $73 \%$ das doses ingeridas de forma abusiva. O nível abusivo é estabelecido como a ingestão em uma única ocasião de 5 doses ou mais para homens e 4 doses ou mais para mulheres 
(Brewer e cols., 2005). Em 2007, 33,6 milhões de brasileiros teriam atingido esse nível de intoxicação, o que representaria $28 \%$ da população total adulta.

Com base nos dados da ACNIELSEN e da POF/2008-2009, foi estimado uma função de demanda Nested Logit e a partir dos coeficientes estimados, foram calculadas as elasticidades própria e preço-cruzada. Com esses resultados, foi possível calcular os impostos com efeito equivalente à Lei Seca no que se refere à queda no consumo entre junho e julho de 2008.

Para as simulações, primeiramente obtivemos uma variação de quantidades a partir de uma determinada elevação de preços. Para tanto, multiplicamos a matriz de elasticidades inversa transposta por um vetor coluna de variação de preços arbitrariamente definido. Assim, chegou-se a um vetor coluna de variação de quantidades prevista, cuja média foi calculada. Então, estabeleceu-se como restrição que a variação média prevista deveria ser igual à variação média observada e permitiu-se o cálculo de variações de preços do vetor coluna que anteriormente fora estabelecido de forma arbitrária

Encontrou-se um imposto equivalente à queda de demanda em 4,56\% decorrente da Lei Seca de, em média, 14,2\% no país. No entanto, mostrou-se que regiões diferentes do país tiveram impactos de magnitudes distintas em resposta ao endurecimento das penalidades aos condutores alcoolizados. Para os estados nordestinos do Ceará, Rio Grande do Norte, Paraíba, Pernambuco, Alagoas, Bahia e Sergipe, houve uma queda na demanda de 1,83\%. O imposto equivalente aos efeitos da Lei Seca para esses estados foi o menor entre as regiões estudadas: $0,55 \%$.

Seguindo esta ordem crescente, temos o estado de São Paulo, excluindo-se a região metropolitana. Essa área apresentou uma queda de 3,26\% na quantidade de litros de cerveja como efeito da aprovação da Lei Seca, o que equivaleria a um aumento de preços em 4,44\%. Já os estados do sul do país reagiram às maiores penalidades previstas para motoristas alcoolizados por meio da redução de 3,17\% no consumo de cervejas. Por meio de simulações, chegou-se a um aumento de preços de 3,74\% como forma de resultar numa queda na demanda na mesma magnitude. 
Nos estados do Rio de Janeiro (exceto região metropolitana), Minas Gerais e Espírito Santo, foi constatada uma queda na demanda de cervejas em 5,50\% no período de aprovação da Lei Seca. Para essas áreas, o imposto equivalente encontrado é mais elevado, sendo de $14,52 \%$ sobre o preço.

Os consumidores das metropolitana de São Paulo e Rio de Janeiro também reduziram a compra por cervejas como resposta à Lei Seca. Os primeiros passaram a consumir 6,99\% menos cervejas de junho de 2008 para julho de 2008, enquanto os últimos reduziram seu consumo em 4,03\%. Essas variações negativas de quantidade poderiam ser obtidas por meio de aplicações de impostos sobre preços de 13,58\% e 15,95\% nas regiões metropolitanas de São Paulo e Rio de Janeiro, respectivamente. Por fim, os estados de Mato Grosso do Sul e Goiás apresentaram a maior variação de preços equivalente. Com a inclusão de um imposto de 17,84\% sobre os preços das cervejas, chegaria-se à queda na demanda observada em $6,36 \%$.

Essas variações negativas na demanda por cervejas como resposta à aprovação da Lei Seca evidendiam que houve um desconhecimento dos consumidores com relação à fiscalização que seria feita pelas autoridades competentes. Devido à incerteza com relação à presença de álcool no sangue após ingestão de bebidas etílicas e possibilidade de ser encontrada a substância no sangue, a resposta imediata dos consumidores ao endurecimento de penalidades foi comprar menos cervejas.

Entretanto, com a implementação de blitz de fiscalização, os condutores passaram a se comunicarem de forma mais frequente, criando mecanismos específicos para burlarem a Lei Seca. Por meio de aplicativos que incluíssem mapas e mensagens, os consumidores sinalizavam uns aos outros a presença de fiscais de alcoolemia no sangue. Essa troca de informações entre infratores é um fator que pode ter tornado os efeitos na quantidade de bebidas etílicas consumidas em decorrência da Lei Seca maiores no entorno da aprovação da política.

Nesse sentido, o aumento de preços via impostos poderia desincentivar comportamentos de risco que derivam do consumo abusivo do álcool de forma mais persistente. Como visto em outros países, essa medida pode acarretar em redução de acidentes de 
trânsito. Ressalta-se que a política tributária pode ser mais um elemento entre as políticas voltadas para os problemas de saúde pública, no entanto, não soluciona sozinha a ocorrência de acidentes. A fiscalização de infrações mantém-se como um fator importante para a melhora dos índices de saúde pública no tráfego. 


\section{Referências}

ANTIDROGAS, S. N. I levantamento nacional sobre os padrões de consumo de álcool na população brasileira. Secretaria Nacional Antidrogas Brasília, 2007.

BABOR, T. e col. (2004). Alcohol: no Ordinary Commodity. Oxford University Press, OMS

BRASIL. Lei n. 11.705, de 19 de junho de 2008. Diário Oficial da República Federativa do Brasil, Brasília, DF, v. 134, n. 248, 19 jun 2008.Seção I, p. 27834-27841A, Brasília. 2008.

BERRY, S. Estimating discrete-choice models of product differentiation. Rand Journal of Economics, v. 25, p. 242-262, 1994.

BERRY, S., LEVINSOHN, J., PAKES, A. Automobile prices in market equilibrium. Econometrica, v. 63, p. 841-890, 1995.

BREWER, R. e cols. . Binge Drinking and Violence. Journal of the American Medical Association, August3, 294(5): 616-619 (2005)

CARDELL, N. S. Extensions of the multinomial logit: the hedonic demand model, the non-independent logit model, and the ranked logit model. Harvard University, 1989

DeAtON, A.; MUELlBAUER, J. An Almost Ideal Demand System The American Economic Review, Vol. 70, No. 3. (Jun., 1980), pp. 312-326.

DAVIS, P. ; GARCÉS, E. Quantitative Techniques for Competition and Antitrust Analysis, 2009

DEJONG, W.; HINGSON, R. Strategies to reduce driving under the influence of alcohol. Rev. Public Health. 1998. 19:359-78

EDWARDS, G. e col. Alcohol Policy and the Public Good. Oxford University Press, OMS (1994).

HAUSMAN, J. A., LEONARD, G. K. Economic analysis of differenticited products mergers using real world data. In: HAUSMAN, J. A., LEONAND, G. K., MASON, G. Law Review, v. 5, n. 3, 1997

HAUSMAN, J.; LEONARD, G.; ZONA, J. A multi-level demand system for differenciated products with an application to beer. Annals of Economics and Statistics No. 34: 159-180, Apr. - Jun., 1994.

HUSE, C.; SALVO, A. Estimation and Identification of Demand and Supply. In: Quantitative Methods Applied to Antitrust and Regulation. SDE, 2006. 
LARAnJeIRA, R.; ROMAnO M. Consenso Brasileiro de Políticas Públicas sobre Álcool. Revista Brasileira de Psiquiatria, v.26, p.68-77 (2004).

LOPES, C. E. M.; MOITA, R. M. S. Demanda por meios de transporte na grande São Paulo: Uma análise de políticas públicas. Insper Working Paper, WPE: 316/2013, São Paulo. 2013.

LUCINDA, C. Modelagem Estrutural de Demanda: Revisão da Literatura e Aplicações. Universidade de São Paulo, 2013.

MCFADDEN, D. Conditional logit analysis of qualitative choice behavior. In: ZAREMBKA, P. (ed.). Frontiers of econometrics. New York: Academic Press, 1974.

Modeling the choice of residential location. In: KARLGVIST, A. et alii (eds.). Spatial interaction theory and planning models. Amsterdam: North-Holland, 1978a.

MC MILLAN, G.P. e LAPHAM, S (2006). Effectiveness of Bans and Laws in Reducing Traffic Deaths: Legalized Sunday Alcohol-Related Crashes and Crash Fatalities in New Mexico. American Journal of Public Health, 96(11):1944-8.

MANNING, W.; BLUMBERG, L.; MOULTON, L. The demand for alcohol: The differential response to price. Journal of Health Economics. 14(2):123-148, Jun 1995

MELONI, J. N. LARANJEIRA, R. (2003). Tracking Alcohol Consumption Over Time. Alcohol Research and Health. 27, 30-38

MELONI, J. N. e LARANJEIRA, R. (2004). Custo Social e de Saúde do COnsumo do Álcool. Revista Brasileira Psiquiátrica, 26 (supl.I):7-10

NAIMI, T. e cols. Binge Drinking among US Adults. Journal of the American Medical Associaion, January1, 289(1):70-77 (2003)

NEVO, A. Measuring market power in the ready-to-eat cereal industry. Econometrica, v. 69, p. 307-342, 2001.

PHEBO, L. e DELlinger, A. M. (1998). Young Driver Involvement in Fatal Motor Vehicle Crashes and Trends in Risk Behaviors. US, 1988-95. Injury Prevention, $4(4): 284-7$

ROSA S.E.S. et al. Panorama do setor de bebidas no Brasil. Rio de Janeiro: BNDES Setorial, n. 23, p. 101-150, 2006.

SAFFER, H., and GROSSMAN, M. Beer taxes, the legal drinking age, and youth motor vehicle fatalities. Journal of Legal Studies 16(2):351-374, 1987a.

M. Drinking age laws and highway mortality rates: Cause and effect. Economic Inquiry 25(3):403-417, 1987b 
Econometric analysis of qualitative response models. In: GRILICHES, Z., INTILLIGATOR, M. (eds.). Handbook of econometrics, Amsterdam: North-Holland, v. III, 1984.

SENAD. I Levantamento Nacional sobre os Padrões de Consumo de Álcool na População Brasileira feito pela Secretaria Nacional Antidrogas. Secretaria Nacional Antidrogas, 2007

SIMON, H.A. Models of Bounded Rationality : Empirically Grounded Economic Reason. MIT Press, Cambridge, MA, 1997a. Vol. 3.

TAXMANA, F.; PIQUERO, A. On preventing drunk driving recidivism: an examination of rehabilitation and punishment approaches. Journal of Criminal Justice 26(2): 129-143, March-April 1998.

TRAIN, K. Discrete choice methods with simulation. [S.l.]: Cambridge university press, 2009.

WORLD HEALTH ORGANIZATION. Reducing Risks, Promoting Healthy Life in: The World Health Report, 2002. 


\section{APÊNDICE}

Referências da POF 2008-2009 para definição de Mercado Potencial abstraídas dos Quadros 63 a 69, referentes aos alimentos.

Tabela 4: POF 2008-2009 1 - Adequação às áreas ACNIELSEN

\begin{tabular}{|c|c|c|c|c|c|c|}
\hline & V2 - COD. DA UF & \multicolumn{4}{|c|}{ V7 - ESTRATO GEOGRÁFICO } & \multirow[t]{2}{*}{ Equivalente NIELSEN } \\
\hline & & Município da Capital & Resto da RM & Resto da UF & RURAL & \\
\hline Ceará & 23 & 1 a 9 & 10 a 12 & 13 a 23 & 24 a 36 & $\mathrm{I}$ \\
\hline Rio Grande do Norte & 24 & 1 e 2 & - & 3 a 8 & 9 a 13 & $\mathrm{I}$ \\
\hline Paraíba & 25 & 1 a 3 & - & 4 a 9 & 10 a 16 & $\mathrm{I}$ \\
\hline Pernambuco & 26 & 1 a 3 & 4 a 6 & 7 a 15 & 16 a 25 & $\mathrm{I}$ \\
\hline Alagoas & 27 & 1 a 3 & - & 4 a 8 & 9 a 13 & $\mathrm{I}$ \\
\hline Sergipe & 28 & 1 e 2 & - & 3 a 7 & 8 a 9 & $\mathrm{I}$ \\
\hline Bahia & 29 & 1 a 6 & 7 a 8 & 9 a 21 & 22 a 36 & $\mathrm{I}$ \\
\hline Minas Gerais & 31 & 1 a 6 & 7 a 9 & 10 a 27 & 28 a 45 & II \\
\hline Espírito Santo & 32 & 1 & - & 2 a 9 & 10 a 14 & II \\
\hline Rio de Janeiro & 33 & 1 a 9 & 10 a 18 & 19 a 30 & 31 a 37 & III e II \\
\hline São Paulo & 35 & 1 a 9 & 10 a 15 & 16 a 30 & 31 a 51 & IV e V \\
\hline Paraná & 41 & 1 a 6 & 7 a 9 & 10 a 18 & 19 a 29 & VI \\
\hline Santa Catarina & 42 & 1 e 2 & - & 3 a 13 & 14 a 23 & VI \\
\hline Rio Grande Do Sul & 43 & 1 a 6 & 7 a 9 & 10 a 18 & 19 a 30 & VI \\
\hline Mato Grosso do Sul & 50 & 1 a 3 & - & 4 a 8 & 9 a 13 & VII \\
\hline Goiás & 52 & 1 a 3 & - & 4 a 17 & 18 a 28 & VII \\
\hline Distrito Federal & 53 & 1 a 7 & - & - & 8 a 9 & VII \\
\hline
\end{tabular}


Tabela 5: POF 2008-2009: Canais de Venda equivalentes a auto-serviços

\begin{tabular}{lcc}
\hline Nome POF & Cod. POF. & Equivalente NIELSEN \\
\hline ARMAZEM & 00501 & Auto-serviço \\
ARMAZEM ATACADISTA & 06704 & Auto-serviço \\
ARMAZEM VAREJISTA & 00514 & Auto-serviço \\
ATACADISTA & 06701 & Auto-serviço \\
BODEGA (ARMAZEM) & 00502 & Auto-serviço \\
CASA DA FARINHA & 00512 & Auto-serviço \\
CASA DE FARINHA & 00511 & Auto-serviço \\
CASA DO NORTE & 00513 & Auto-serviço \\
CEREALISTA & 00503 & Auto-serviço \\
CEREALISTA ATACADISTA & 06705 & Auto-serviço \\
FREE SHOP (LOJA DE IMPORTADOS) & 07003 & Auto-serviço \\
HIPERMERCADO & 00201 & Auto-serviço \\
HIPERMERCADO ATACADISTA & 06703 & Auto-serviço \\
HORTIFRUTI & 01203 & Auto-serviço \\
LAN HOUSE (LOJA INTERNET) & 09112 & Auto-serviço \\
LOJA ATACADISTA & 06706 & Auto-serviço \\
LOJA DE BALAS & 00407 & Auto-serviço \\
LOJA DE BALAS, DOCES E BOMBONS & 00405 & Auto-serviço \\
LOJA DE CONVENIENCIA & 05602 & Auto-serviço \\
LOJA DO CONFITO & 00408 & Auto-serviço \\
MERCADINHO & 00508 & Auto-serviço \\
MERCADO & 00509 & Auto-serviço \\
MERCADO (ARMAZEM) & 00506 & Auto-serviço \\
MINIMERCADO (ARMAZEM) & 00507 & Auto-serviço \\
POSTO DE COMBUSTIVEL & 05603 & Auto-serviço \\
POSTO DE COMBUSTIVEL (LOJA DE CONVENIENCIA) & 05601 & Auto-serviço \\
POSTO DE GASOLINA & 05604 & Auto-serviço \\
SECOS E MOLHADOS (ARMAZEM) & 00510 & Auto-serviço \\
SUPERMERCADO & 00101 & Auto-serviço \\
SUPERMERCADO ATACADISTA & 06702 & Auto-serviço
\end{tabular}


Tabela 6: POF 2008-2009: Canais de Venda equivalentes a bares

\begin{tabular}{|c|c|c|}
\hline Nome POF & Cod. POF. & Equivalente NIELSEN \\
\hline ADEGA & 02005 & Bar \\
\hline BAR & 01114 & Bar \\
\hline BAR E RESTAURANTE & 04906 & Bar \\
\hline BAR, LANCHONETE & 01101 & Bar \\
\hline BARRACA DE PRAIA & 01017 & Bar \\
\hline BARZINHO & 01115 & Bar \\
\hline BIROSCA & 01104 & Bar \\
\hline BOTECO & 01105 & Bar \\
\hline BOTEQUIM (BAR) & 01106 & Bar \\
\hline BUFFET & 04913 & Bar \\
\hline CACHACARIA & 01124 & Bar \\
\hline CAFE E BAR & 01107 & Bar \\
\hline CAFETERIA & 01111 & Bar \\
\hline CARRINHO DE ALIMENTOS & 01018 & Bar \\
\hline CARROCINHA DE ALIMENTOS & 01019 & Bar \\
\hline CASA DE ASSADOS & 04916 & Bar \\
\hline CASA DE COMIDAS TIPICAS & 04909 & Bar \\
\hline CASA DE JOGOS & 03803 & Bar \\
\hline CASA DE MASSAS & 04905 & Bar \\
\hline CHOPERIA & 01116 & Bar \\
\hline COPO SUJO & 01125 & Bar \\
\hline CREPERIA & 01118 & Bar \\
\hline DELIVERY DE COMIDA CHINESA & 04917 & Bar \\
\hline ESTABELECIMENTO CULTURAL & 09501 & Bar \\
\hline ESTABELECIMENTO DE EVENTOS E DIVERSAO & 09701 & Bar \\
\hline FLIPERAMA & 03802 & Bar \\
\hline FLUTUANTE COMERCIAL & 01029 & Bar \\
\hline LANCHERIA & 01109 & Bar \\
\hline LANCHONETE & 01102 & Bar \\
\hline LANCHONETE POPULAR & 09301 & Bar \\
\hline LOJA DE SALGADINHOS (LANCHE) & 01112 & Bar \\
\hline MARMITARIA (SERVE REFEICOES) & 04908 & Bar \\
\hline MARMITEX & 04912 & Bar \\
\hline MUSEU & 09505 & Bar \\
\hline PASTELARIA & 01103 & Bar \\
\hline PEIXARIA (RESTAURANTE) & 04914 & Bar \\
\hline PRAIA & 07711 & Bar \\
\hline PRESTAMISTA & 01028 & Bar \\
\hline PUB & 01121 & Bar \\
\hline RESTAURANTE DE COMIDAS TIPICAS & 04910 & Bar \\
\hline RESTAURANTE POPULAR & 09201 & Bar \\
\hline RESTAURENTE E BAR & 04907 & Bar \\
\hline ROTISSERIA & 04911 & Bar \\
\hline SCOTH BAR & 01113 & Bar \\
\hline SELF SERVICE & 04915 & Bar \\
\hline SORVETERIA & 02701 & Bar \\
\hline TABERNA & 00603 & BAr \\
\hline TAPIOQUEIRA & 01016 & Bar \\
\hline TENDINHA (BAR) & 01110 & Bar \\
\hline TREILLER OU QUIOSQUE & 01009 & Bar \\
\hline WISQUERIA & 01120 & Bar \\
\hline
\end{tabular}


Tabela 7: POF 2008-2009: Canais de Venda equivalentes a locais tradicionais

\begin{tabular}{lcc}
\hline Nome POF & Cod. POF. & Equivalente NIELSEN \\
\hline BISCOITERIA & 00406 & Tradicional \\
BODEGA (MERCEARIA) & 00604 & Tradicional \\
BOMBONIERE & 00403 & Tradicional \\
CASA DE BOLO & 00411 & Tradicional \\
CASA DE DOCES & 00412 & Tradicional \\
CONFEITARIA & 00409 & Tradicional \\
CONFEITARIA, DOCERIA & 00401 & Tradicional \\
DELICATESSE & 00404 & Tradicional \\
DEPOSITO DE PAES & 00302 & Tradicional \\
DISTRIBUIDORA DE ALIMENTOS & 02013 & Tradicional \\
DISTRIBUIDORA DE BEBIDAS & 02008 & Tradicional \\
DOCERIA & 00402 & Tradicional \\
FABRICA DE BOMBOM ARTESANAL & 00410 & Tradicional \\
LOJA DE BISCOITOS & 00414 & Tradicional \\
LOJA DE BOLO & 00413 & Tradicional \\
LOJA DE FABRICA & 05903 & Tradicional \\
MERCADO MUNICIPAL & 02603 & Tradicional \\
MERCADO POPULAR PUBLICO & 02607 & Tradicional \\
MERCADO PUBLICO POPULAR & 02608 & Tradicional \\
PADARIA & 00301 & Tradicional \\
PANIFICADORA & 00305 & Tradicional \\
PANIFICIO & 00304 & Tradicional \\
VINICULA & 05920 & Tradicional
\end{tabular}


Tabela 8: POF 2008-2009: Produtos não alcoólicos

\begin{tabular}{|c|c|c|c|}
\hline Grupo POF & Cod. POF. & Nome POF & Equivalente NIELSEN \\
\hline 82 & 00901 & REFRIGERANTE MINUANO & Água \\
\hline 82 & 00902 & MINUANO & Água \\
\hline 82 & 01001 & REFRIGERANTE AGUA MINERAL & Água \\
\hline 82 & 01002 & REFRIGERANTE MINALBA & Água \\
\hline 82 & 01003 & MINALBA & Água \\
\hline 82 & 01004 & AGUA MINERAL & Água \\
\hline 82 & 01005 & AGUA MINERAL SEM GAS & Água \\
\hline 82 & 01006 & AGUA COM GAS & Água \\
\hline 82 & 01007 & AGUA MINERAL COM GAS & Água \\
\hline 82 & 01008 & AGUA FLUORADA & Água \\
\hline 82 & 01009 & AGUA PURIFICADA & Água \\
\hline 82 & 01010 & AGUA MINERAL SABOR LIMAO & Água \\
\hline 82 & 04501 & CHOCOLATE ENGARRAFADO OU ENCARTONADO & Bebida láctea \\
\hline 82 & 04502 & CHOCOMILK ENGARRAFADO & Bebida láctea \\
\hline 82 & 04503 & CHOCOMILK ENCARTONADO & Bebida láctea \\
\hline 82 & 04504 & CHOCOLATE LIQUIDO & Bebida láctea \\
\hline 82 & 11201 & CHOCOLATE ENGARRAFADO OU ENCARTONADO LIGHT & Bebida láctea \\
\hline 82 & 11202 & CHOCOMILK ENGARRAFADO LIGHT & Bebida láctea \\
\hline 82 & 11203 & CHOCOMILK ENCARTONADO LIGHT & Bebida láctea \\
\hline 82 & 11301 & CHOCOLATE ENGARRAFADO OU ENCARTONADO DIET & Bebida láctea \\
\hline 82 & 11302 & CHOCOMILK ENGARRAFADO DIET & Bebida láctea \\
\hline 82 & 11303 & CHOCOMILK ENCARTONADO DIET & Bebida láctea \\
\hline 82 & 11304 & CHOCOLATE ENGARRAFADO OU ENCARTONADO DIETETICO & Bebida láctea \\
\hline 82 & 11305 & CHOCOMILK ENGARRAFADO LIGHT DIETETICO & Bebida láctea \\
\hline 82 & 11306 & CHOCOMILK ENCARTONADO LIGHT DIETETICO & Bebida láctea \\
\hline 82 & 03701 & CAFE EM GRAO & Café \\
\hline 82 & 03901 & CAFE COM LEITE EM PO & Café \\
\hline 82 & 05001 & CAFE DESCAFEINADO & Café \\
\hline 82 & 06401 & CAFE CAPUCCINO SOLUVEL & Café \\
\hline 82 & 06402 & CAFE SOLUVEL CAPUCCINO & Café \\
\hline 82 & 10601 & CAFE MOIDO ORGANICO & Café \\
\hline
\end{tabular}




\begin{tabular}{|c|c|c|c|}
\hline Grupo POF & Cod. POF. & Nome POF & Equivalente NIELSEN \\
\hline 82 & 10602 & PO DE CAFE ORGANICO & Café \\
\hline 82 & 10701 & CAFE SOLUVEL ORGANICO & Café \\
\hline 82 & 10702 & NESCAFE ORGANICO & Café \\
\hline 82 & 10801 & CAFE EM GRAO ORGANICO & Café \\
\hline 82 & 10901 & CAFE DESCAFEINADO ORGANICO & Café \\
\hline 82 & 12401 & CAFE CAPUCCINO SOLUVEL LIGHT & Café \\
\hline 82 & 12402 & CAFE SOLUVEL CAPUCCINO LIGHT & Café \\
\hline 82 & 12501 & CAFE CAPUCCINO SOLUVEL DIET & Café \\
\hline 82 & 12502 & CAFE SOLUVEL CAPUCCINO DIET & Café \\
\hline 82 & 12503 & CAFE CAPUCCINO SOLUVEL DIETETICO & Café \\
\hline 82 & 12504 & CAFE SOLUVEL CAPUCCINO DIETETICO & Café \\
\hline 82 & 02503 & CAFE EM PO & Café \\
\hline 82 & 02601 & CAFE SOLUVEL & Café \\
\hline 82 & 02602 & NESCAFE & Café \\
\hline 82 & 05901 & BEBIDA ENERGETICA & Energético \\
\hline 82 & 05803 & GATORADE & Isotônico \\
\hline 82 & 05805 & BEBIDA ISOTONICA & Isotônico \\
\hline 82 & 05806 & ISOTONICO & Isotônico \\
\hline 82 & 02001 & CALDO DE CANA & Outro \\
\hline 82 & 02002 & GARAPA & Outro \\
\hline 82 & 02101 & AGUA DE COCO & Outro \\
\hline 82 & 02501 & CAFE MOIDO & Outro \\
\hline 82 & 02502 & PO DE CAFE & Outro \\
\hline 82 & 03401 & LEVEDO DE CERVEJA & Outro \\
\hline 82 & 03402 & CERVEJA EM PO & Outro \\
\hline 82 & 03601 & CAFE DE CEVADA & Outro \\
\hline 82 & 03602 & CEVADA CAFE & Outro \\
\hline 82 & 03603 & CEVADA EM PO & Outro \\
\hline 82 & 03604 & CEVADA MOIDA & Outro \\
\hline 82 & 05802 & TAFFMAN E & Outro \\
\hline 82 & 05804 & SNAPPLE & Outro \\
\hline 82 & 06001 & BEBIDA NAO-ALCOOLICA NAO-ESPECIFICADA & Outro \\
\hline 82 & 14601 & AROMATIZANTE DE BEBIDAS & Outro \\
\hline 82 & 14602 & SABORIZADOR DE LEITE & Outro \\
\hline
\end{tabular}




\begin{tabular}{|c|c|c|c|}
\hline Grupo POF & Cod. POF. & Nome POF & Equivalente NIELSEN \\
\hline 82 & 01103 & MATE COURO & Chá \\
\hline 82 & 01104 & MATE & Chá \\
\hline 82 & 01105 & MATE LIMAO & Chá \\
\hline 82 & 01106 & MATE PESSEGO & Chá \\
\hline 82 & 01107 & PESSEGO MATE & Chá \\
\hline 82 & 02701 & CHA PRETO & Chá \\
\hline 82 & 02702 & CHA DA INDIA & Chá \\
\hline 82 & 02703 & CHA JAPONES & Chá \\
\hline 82 & 02801 & CHA MATE & Chá \\
\hline 82 & 02802 & MATE ERVA & Chá \\
\hline 82 & 02803 & ERVA MATE & Chá \\
\hline 82 & 02804 & CHIMARRAO & Chá \\
\hline 82 & 02805 & ERVA DE TERERE & Chá \\
\hline 82 & 02901 & ERVA DOCE CHA & Chá \\
\hline 82 & 02902 & CHA DE ERVA DOCE & Chá \\
\hline 82 & 02903 & ANIZ CHA & Chá \\
\hline 82 & 02904 & CHA DE ANIZ & Chá \\
\hline 82 & 03001 & HORTELA CHA & Chá \\
\hline 82 & 03002 & CHA DE HORTELA & Chá \\
\hline 82 & 03101 & CANELA CHA & Chá \\
\hline 82 & 03102 & CHA DE CANELA & Chá \\
\hline 82 & 03201 & CAMOMILA CHA & Chá \\
\hline 82 & 03202 & CHA DE CAMOMILA & Chá \\
\hline 82 & 03301 & ERVA CIDREIRA CHA & Chá \\
\hline 82 & 03302 & CHA DE ERVA CIDREIRA & Chá \\
\hline 82 & 03303 & CHA DE CIDREIRA & Chá \\
\hline 82 & 04401 & MARCELA CHA & Chá \\
\hline 82 & 04402 & CHA DE MARCELA & Chá \\
\hline 82 & 05201 & CHA DIET & Chá \\
\hline 82 & 05202 & CHA VITA SANFER & Chá \\
\hline 82 & 05203 & CHA EMAGRECEDOR & Chá \\
\hline 82 & 05204 & CHA DIETETICO & Chá \\
\hline 82 & 05205 & CHA VITA SANFER DIET & Chá \\
\hline 82 & 05206 & CHA EMAGRECEDOR DIET & Chá \\
\hline 82 & 05207 & CHA VITA SANFER DIETETICO & Chá \\
\hline 82 & 05208 & CHA EMAGRECEDOR DIETETICO & Chá \\
\hline 82 & 05601 & MULTIERVAS CHA & Chá \\
\hline 82 & 05602 & CHA MULTIERVAS & Chá \\
\hline
\end{tabular}




\begin{tabular}{|c|c|c|c|}
\hline Grupo POF & Cod. POF. & Nome POF & Equivalente NIELSEN \\
\hline 82 & 06101 & OUTRO CHA & Chá \\
\hline 82 & 06102 & CHA OUTRO & Chá \\
\hline 82 & 06301 & CHA NAO-ESPECIFICADO & Chá \\
\hline 82 & 06501 & ARRUDA CHA & Chá \\
\hline 82 & 06502 & ARRUDA EM FOLHA & Chá \\
\hline 82 & 06503 & FOLHA DE ARRUDA & Chá \\
\hline 82 & 06504 & CHA DE ARRUDA & Chá \\
\hline 82 & 06601 & BOLDO CHA & Chá \\
\hline 82 & 06602 & CHA DE BOLDO & Chá \\
\hline 82 & 12601 & CHA PRETO LIGHT & Chá \\
\hline 82 & 12602 & CHA DA INDIA LIGHT & Chá \\
\hline 82 & 12603 & CHA JAPONES LIGHT & Chá \\
\hline 82 & 12701 & CHA MATE LIGHT & Chá \\
\hline 82 & 12702 & MATE ERVA LIGHT & Chá \\
\hline 82 & 12703 & ERVA MATE LIGHT & Chá \\
\hline 82 & 12801 & CHA MATE DIET & Chá \\
\hline 82 & 12802 & MATE ERVA DIET & Chá \\
\hline 82 & 12803 & ERVA MATE DIET & Chá \\
\hline 82 & 12804 & CHA MATE DIETETICO & Chá \\
\hline 82 & 12805 & MATE ERVA DIETETICO & Chá \\
\hline 82 & 12806 & ERVA MATE DIETETICA & Chá \\
\hline 82 & 13001 & ERVA MATE ORGANICA & Chá \\
\hline 82 & 13002 & MATE ERVA ORGANICO & Chá \\
\hline 82 & 13003 & CHA MATE ORGANICO & Chá \\
\hline 82 & 13004 & CHIMARRAO ORGANICO & Chá \\
\hline 82 & 13101 & CHA DE LIMAO & Chá \\
\hline 82 & 13201 & CHA DE ALFAZEMA & Chá \\
\hline 82 & 13301 & CHA VERDE & Chá \\
\hline 82 & 13501 & CHA DE MACA & Chá \\
\hline 82 & 13701 & CHA DE PESSEGO & Chá \\
\hline 82 & 13801 & CHA DE SENE & Chá \\
\hline 82 & 13901 & MATE COURO DIET & Chá \\
\hline 82 & 14201 & CHA DE ENDRO & Chá \\
\hline 82 & 14401 & BABOSA EM FOLHA & Chá \\
\hline 82 & 14801 & CHA DE ABACAXI & Chá \\
\hline 82 & 14901 & CHA DE MORANGO & Chá \\
\hline 82 & 15101 & CHA DE MALVA & Chá \\
\hline 82 & 15301 & CHA DE CARQUEJA & Chá \\
\hline 82 & 15401 & FOLHAS DE AMORA (CHA) & Chá \\
\hline
\end{tabular}




\begin{tabular}{|c|c|c|c|}
\hline Grupo POF & Cod. POF. & Nome POF & Equivalente NIELSEN \\
\hline 82 & 00101 & REFRIGERANTE DE COLA & Refrigerante \\
\hline 82 & 00102 & COCA COLA & Refrigerante \\
\hline 82 & 00103 & REFRIGERANTE COCA COLA & Refrigerante \\
\hline 82 & 00104 & REFRIGERANTE PEPSI & Refrigerante \\
\hline 82 & 00105 & PEPSI & Refrigerante \\
\hline 82 & 00106 & PEPSI COLA & Refrigerante \\
\hline 82 & 00107 & REFRIGERANTE PEPSI COLA & Refrigerante \\
\hline 82 & 00201 & REFRIGERANTE DE LARANJA & Refrigerante \\
\hline 82 & 00202 & FANTA LARANJA & Refrigerante \\
\hline 82 & 00203 & REFRIGERANTE CRUSH & Refrigerante \\
\hline 82 & 00204 & CRUSH & Refrigerante \\
\hline 82 & 00205 & REFRIGERANTE MIRINDA & Refrigerante \\
\hline 82 & 00206 & MIRINDA & Refrigerante \\
\hline 82 & 00207 & REFRIGERANTE SUKITA & Refrigerante \\
\hline 82 & 00208 & SUKITA & Refrigerante \\
\hline 82 & 00209 & REFRIGERANTE POP LARANJA & Refrigerante \\
\hline 82 & 00210 & POP LARANJA & Refrigerante \\
\hline 82 & 00301 & REFRIGERANTE DE GUARANA & Refrigerante \\
\hline 82 & 00302 & GUARANA & Refrigerante \\
\hline 82 & 00303 & REFRIGERANTE FRATELLY VITA & Refrigerante \\
\hline 82 & 00304 & FRATELLY VITA & Refrigerante \\
\hline 82 & 00305 & GUARAVITA & Refrigerante \\
\hline 82 & 00306 & GUARAVITON & Refrigerante \\
\hline 82 & 00307 & REFRIGERANTE GUARANA & Refrigerante \\
\hline 82 & 00401 & REFRIGERANTE DE LIMAO & Refrigerante \\
\hline 82 & 00402 & REFRIGERANTE SODA LIMONADA & Refrigerante \\
\hline 82 & 00403 & SODA LIMONADA & Refrigerante \\
\hline 82 & 00404 & LIMAO REFRIGERANTE & Refrigerante \\
\hline 82 & 00405 & REFRIGERANTE LIMAO & Refrigerante \\
\hline 82 & 00406 & REFRIGERANTE SPRIT & Refrigerante \\
\hline 82 & 00407 & SPRIT REFRIGERANTE & Refrigerante \\
\hline 82 & 00408 & REFRIGERANTE FANTA LIMAO & Refrigerante \\
\hline 82 & 00409 & REFRIGERANTE GASOSA & Refrigerante \\
\hline 82 & 00410 & GASOSA & Refrigerante \\
\hline 82 & 00501 & REFRIGERANTE DE UVA & Refrigerante \\
\hline 82 & 00502 & REFRIGERANTE FANTA UVA & Refrigerante \\
\hline 82 & 00503 & REFRIGERANTE GRAPETE & Refrigerante \\
\hline 82 & 00504 & GRAPETE & Refrigerante \\
\hline 82 & 00505 & FANTA UVA & Refrigerante \\
\hline
\end{tabular}




\begin{tabular}{|c|c|c|c|}
\hline Grupo POF & Cod. POF. & Nome POF & Equivalente NIELSEN \\
\hline 82 & 00506 & BEBIDA MISTA DE UVA & Refrigerante \\
\hline 82 & 00601 & REFRIGERANTE MINEIRINHO & Refrigerante \\
\hline 82 & 00602 & MINEIRINHO & Refrigerante \\
\hline 82 & 00701 & REFRIGERANTE DE COLA LIGHT & Refrigerante \\
\hline 82 & 00702 & COCA COLA LIGHT & Refrigerante \\
\hline 82 & 00703 & REFRIGERANTE COCA COLA LIGHT & Refrigerante \\
\hline 82 & 00801 & REFRIGERANTE DE COLA DIET & Refrigerante \\
\hline 82 & 00802 & REFRIGERANTE PEPSI DIET & Refrigerante \\
\hline 82 & 00803 & PEPSI DIET & Refrigerante \\
\hline 82 & 00804 & PEPSI COLA DIET & Refrigerante \\
\hline 82 & 00805 & REFRIGERANTE PEPSI COLA DIET & Refrigerante \\
\hline 82 & 00806 & REFRIGERANTE DE COLA DIETETICO & Refrigerante \\
\hline 82 & 00807 & REFRIGERANTE PEPSI DIETETICO & Refrigerante \\
\hline 82 & 00808 & PEPSI DIETETICA & Refrigerante \\
\hline 82 & 00809 & PEPSI COLA DIETETICA & Refrigerante \\
\hline 82 & 00810 & REFRIGERANTE PEPSI COLA DIETETICO & Refrigerante \\
\hline 82 & 01011 & H2O SABOR LIMAO & Refrigerante \\
\hline 82 & 01012 & AGUA COM GAS E LIMAO & Refrigerante \\
\hline 82 & 01013 & AGUA COM GAS SABOR LIMAO & Refrigerante \\
\hline 82 & 01014 & AGUA MINERAL SABOR TANGERINA & Refrigerante \\
\hline 82 & 01015 & AGUA COM SABOR GASEIFICADA & Refrigerante \\
\hline 82 & 01016 & AGUA MINERAL SABOR LARANJA & Refrigerante \\
\hline 82 & 01101 & REFRIGERANTE DE MATE & Refrigerante \\
\hline 82 & 01102 & REFRIGERANTE MATE COURO & Refrigerante \\
\hline 82 & 01201 & REFRIGERANTE BIDU & Refrigerante \\
\hline 82 & 01202 & BIDU & Refrigerante \\
\hline 82 & 01301 & REFRIGERANTE JAO & Refrigerante \\
\hline 82 & 01302 & $\mathrm{JAO}$ & Refrigerante \\
\hline 82 & 01401 & REFRIGERANTE ALOA & Refrigerante \\
\hline 82 & 01402 & ALOA & Refrigerante \\
\hline 82 & 01501 & REFRIGERANTE DE LARANJA LIGHT & Refrigerante \\
\hline 82 & 01502 & FANTA LARANJA LIGHT & Refrigerante \\
\hline 82 & 01503 & REFRIGERANTE CRUSH LIGHT & Refrigerante \\
\hline 82 & 01504 & CRUSH LIGHT & Refrigerante \\
\hline 82 & 01505 & REFRIGERANTE MIRINDA LIGHT & Refrigerante \\
\hline 82 & 01506 & MIRINDA LIGHT & Refrigerante \\
\hline 82 & 01507 & REFRIGERANTE SUKITA LIGHT & Refrigerante \\
\hline 82 & 01508 & SUKITA LIGHT & Refrigerante \\
\hline
\end{tabular}




\begin{tabular}{|c|c|c|c|}
\hline Grupo POF & Cod. POF. & Nome POF & Equivalente NIELSEN \\
\hline 82 & 01604 & FRATELLY VITA LIGHT & Refrigerante \\
\hline 82 & 01701 & REFRIGERANTE XODO DA BAHIA & Refrigerante \\
\hline 82 & 01702 & XODO DA BAHIA & Refrigerante \\
\hline 82 & 01801 & REFRIGERANTE TUBAINA & Refrigerante \\
\hline 82 & 01802 & TUBAINA & Refrigerante \\
\hline 82 & 01901 & REFRIGERANTE TUBAINA LIGHT & Refrigerante \\
\hline 82 & 01902 & TUBAINA LIGHT & Refrigerante \\
\hline 82 & 03501 & REFRIGERANTE NAO-ESPECIFICADO & Refrigerante \\
\hline 82 & 04001 & REFRIGERANTE DE MACA LIGHT & Refrigerante \\
\hline 82 & 04002 & MACA REFRIGERANTE LIGHT & Refrigerante \\
\hline 82 & 04003 & FANTA MACA LIGHT & Refrigerante \\
\hline 82 & 04101 & REFRIGERANTE DE MACA & Refrigerante \\
\hline 82 & 04102 & MACA REFRIGERANTE & Refrigerante \\
\hline 82 & 04103 & FANTA MACA & Refrigerante \\
\hline 82 & 04104 & BEBIDA MISTA DE MACA & Refrigerante \\
\hline 82 & 04201 & REFRIGERANTE DE TUTI FRUTI & Refrigerante \\
\hline 82 & 04202 & TUTI FRUTI REFRIGERANTE & Refrigerante \\
\hline 82 & 04301 & REFRIGERANTE DE TANGERINA & Refrigerante \\
\hline 82 & 04302 & TANGERINA REFRIGERANTE & Refrigerante \\
\hline 82 & 04601 & REFRIGERANTE DE CAJU & Refrigerante \\
\hline 82 & 04602 & CAJU REFRIGERANTE & Refrigerante \\
\hline 82 & 04603 & CAJUINA & Refrigerante \\
\hline 82 & 04901 & REFRIGERANTE AGUA TONICA & Refrigerante \\
\hline 82 & 04902 & AGUA TONICA & Refrigerante \\
\hline 82 & 04903 & REFRIGERANTE DE QUININO & Refrigerante \\
\hline 82 & 05401 & REFRIGERANTE PARAGUAI & Refrigerante \\
\hline 82 & 05402 & PARAGUAI REFRIGERANTE & Refrigerante \\
\hline 82 & 05501 & REFRIGERANTE GOIANINHA & Refrigerante \\
\hline 82 & 05502 & GOIANINHA REFRIGERANTE & Refrigerante \\
\hline 82 & 05701 & REFRIGERANTE REAL & Refrigerante \\
\hline 82 & 05702 & REAL REFRIGERANTE & Refrigerante \\
\hline 82 & 05801 & REFRIGERANTE ENERGETICO & Refrigerante \\
\hline 82 & 06701 & REFRIGERANTE CITRICO & Refrigerante \\
\hline 82 & 06702 & FANTA CITRUS & Refrigerante \\
\hline 82 & 06801 & REFRIGERANTE DE ABACAXI & Refrigerante \\
\hline 82 & 06901 & REFRIGERANTE DE ABACAXI COM GUARANA & Refrigerante \\
\hline 82 & 07001 & REFRIGERANTE DE FRAMBOESA & Refrigerante \\
\hline 82 & 07101 & REFRIGERANTE DE MORANGO & Refrigerante \\
\hline
\end{tabular}




\begin{tabular}{|c|c|c|c|}
\hline Grupo POF & Cod. POF. & Nome POF & Equivalente NIELSEN \\
\hline 82 & 07201 & REFRIGERANTE DE MARACUJA & Refrigerante \\
\hline 82 & 07301 & REFRIGERANTE DE GENGIBRE & Refrigerante \\
\hline 82 & 07401 & REFRIGERANTE DE GUARANA DIET & Refrigerante \\
\hline 82 & 07402 & GUARANA DIET & Refrigerante \\
\hline 82 & 07403 & REFRIGERANTE DE GUARANA DIETETICO & Refrigerante \\
\hline 82 & 07404 & GUARANA DIETETICO & Refrigerante \\
\hline 82 & 07405 & REFRIGERANTE DE GUARANA ZERO & Refrigerante \\
\hline 82 & 07406 & GUARANA ZERO & Refrigerante \\
\hline 82 & 07501 & REFRIGERANTE DE LIMAO LIGHT & Refrigerante \\
\hline 82 & 07502 & REFRIGERANTE SODA LIMONADA LIGHT & Refrigerante \\
\hline 82 & 07503 & SODA LIMONADA LIGHT & Refrigerante \\
\hline 82 & 07504 & LIMAO REFRIGERANTE LIGHT & Refrigerante \\
\hline 82 & 07505 & REFRIGERANTE LIMAO LIGHT & Refrigerante \\
\hline 82 & 07506 & REFRIGERANTE FANTA LIMAO LIGHT & Refrigerante \\
\hline 82 & 07507 & REFRIGERANTE GASOSA LIGHT & Refrigerante \\
\hline 82 & 07508 & GASOSA LIGHT & Refrigerante \\
\hline 82 & 07601 & REFRIGERANTE DE LIMAO DIET & Refrigerante \\
\hline 82 & 07602 & REFRIGERANTE SPRIT DIET & Refrigerante \\
\hline 82 & 07603 & SPRIT REFRIGERANTE DIET & Refrigerante \\
\hline 82 & 07604 & REFRIGERANTE DE LIMAO DIETETICO & Refrigerante \\
\hline 82 & 07605 & REFRIGERANTE SPRIT DIETETICO & Refrigerante \\
\hline 82 & 07606 & SPRIT REFRIGERANTE DIETETICO & Refrigerante \\
\hline 82 & 07701 & REFRIGERANTE DE UVA LIGHT & Refrigerante \\
\hline 82 & 07702 & REFRIGERANTE FANTA UVA LIGHT & Refrigerante \\
\hline 82 & 07703 & REFRIGERANTE GRAPETE LIGHT & Refrigerante \\
\hline 82 & 07704 & GRAPETE LIGHT & Refrigerante \\
\hline 82 & 07705 & FANTA UVA LIGHT & Refrigerante \\
\hline 82 & 07801 & REFRIGERANTE MINEIRINHO LIGHT & Refrigerante \\
\hline 82 & 07802 & MINEIRINHO LIGHT & Refrigerante \\
\hline 82 & 07901 & REFRIGERANTE MINUANO LIGHT & Refrigerante \\
\hline 82 & 07902 & MINUANO LIGHT & Refrigerante \\
\hline 82 & 08101 & REFRIGERANTE DE MATE LIGHT & Refrigerante \\
\hline 82 & 08102 & REFRIGERANTE MATE COURO LIGHT & Refrigerante \\
\hline
\end{tabular}




\begin{tabular}{|c|c|c|c|}
\hline Grupo POF & Cod. POF. & Nome POF & Equivalente NIELSEN \\
\hline 82 & 08103 & MATE COURO LIGHT & Chá \\
\hline 82 & 08104 & MATE LIGHT & Chá \\
\hline 82 & 08105 & MATE LIMAO LIGHT & Chá \\
\hline 82 & 08106 & MATE PESSEGO LIGHT & Chá \\
\hline 82 & 08201 & REFRIGERANTE BIDU LIGHT & Refrigerante \\
\hline 82 & 08202 & BIDU LIGHT & Refrigerante \\
\hline 82 & 08301 & REFRIGERANTE JAO LIGHT & Refrigerante \\
\hline 82 & 08302 & JAO LIGHT & Refrigerante \\
\hline 82 & 08401 & REFRIGERANTE ALOA LIGHT & Refrigerante \\
\hline 82 & 08402 & ALOA LIGHT & Refrigerante \\
\hline 82 & 08501 & REFRIGERANTE XODO DA BAHIA LIGHT & Refrigerante \\
\hline 82 & 08502 & XODO DA BAHIA LIGHT & Refrigerante \\
\hline 82 & 08601 & CAFE COM LEITE SOLUVEL & Refrigerante \\
\hline 82 & 08701 & REFRIGERANTE DE TUTI FRUTI LIGHT & Refrigerante \\
\hline 82 & 08702 & TUTI FRUTI REFRIGERANTE LIGHT & Refrigerante \\
\hline 82 & 08801 & REFRIGERANTE DE TANGERINA LIGHT & Refrigerante \\
\hline 82 & 08802 & TANGERINA REFRIGERANTE LIGHT & Refrigerante \\
\hline 82 & 08901 & REFRIGERANTE DE CAJU LIGHT & Refrigerante \\
\hline 82 & 08902 & CAJU REFRIGERANTE LIGHT & Refrigerante \\
\hline 82 & 08903 & CAJUINA LIGHT & Refrigerante \\
\hline 82 & 09001 & REFRIGERANTE AGUA TONICA LIGHT & Refrigerante \\
\hline 82 & 09002 & AGUA TONICA LIGHT & Refrigerante \\
\hline 82 & 09003 & REFRIGERANTE DE QUININO LIGHT & Refrigerante \\
\hline 82 & 09101 & REFRIGERANTE PARAGUAI LIGHT & Refrigerante \\
\hline 82 & 09102 & PARAGUAI REFRIGERANTE LIGHT & Refrigerante \\
\hline 82 & 09201 & REFRIGERANTE GOIANINHA LIGHT & Refrigerante \\
\hline 82 & 09202 & GOIANINHA REFRIGERANTE LIGHT & Refrigerante \\
\hline 82 & 09301 & REFRIGERANTE REAL LIGHT & Refrigerante \\
\hline 82 & 09302 & REAL REFRIGERANTE LIGHT & Refrigerante \\
\hline 82 & 09401 & REFRIGERANTE CITRICO LIGHT & Refrigerante \\
\hline 82 & 09402 & FANTA CITRUS LIGHT & Refrigerante \\
\hline 82 & 09501 & REFRIGERANTE DE ABACAXI LIGHT & Refrigerante \\
\hline 82 & 09601 & REFRIGERANTE DE ABACAXI COM GUARANA LIGHT & Refrigerante \\
\hline 82 & 09701 & REFRIGERANTE DE FRAMBOESA LIGHT & Refrigerante \\
\hline 82 & 09801 & REFRIGERANTE DE MORANGO LIGHT & Refrigerante \\
\hline 82 & 09901 & REFRIGERANTE DE MARACUJA LIGHT & Refrigerante \\
\hline 82 & 10001 & REFRIGERANTE DE GENGIBRE LIGHT & Refrigerante \\
\hline 82 & 12901 & REFRIGERANTE AGUA TONICA DIET & Refrigerante \\
\hline
\end{tabular}




\begin{tabular}{|c|c|c|c|}
\hline Grupo POF & Cod. POF. & Nome POF & Equivalente NIELSEN \\
\hline 82 & 12902 & AGUA TONICA DIET & Refrigerante \\
\hline 82 & 12903 & REFRIGERANTE DE QUININO DIET & Refrigerante \\
\hline 82 & 12904 & REFRIGERANTE AGUA TONICA DIETETICA & Refrigerante \\
\hline 82 & 12905 & AGUA TONICA DIETETICA & Refrigerante \\
\hline 82 & 12906 & REFRIGERANTE DE QUININO DIETETICO & Refrigerante \\
\hline 82 & 13401 & COCA COLA ZERO & Refrigerante \\
\hline 82 & 13402 & COCA COLA DIET & Refrigerante \\
\hline 82 & 13403 & REFRIGERANTE COCA COLA ZERO & Refrigerante \\
\hline 82 & 14001 & REFRIGERANTE NAO-ESPECIFICADO DIET & Refrigerante \\
\hline 82 & 14101 & REFRIGERANTE NAO-ESPECIFICADO LIGHT & Refrigerante \\
\hline 82 & 14501 & REFRIGERANTE DE GENGIBRE DIET & Refrigerante \\
\hline 82 & 14701 & REFRIGERANTE JESUS & Refrigerante \\
\hline 82 & 15001 & REFRIGERANTE GOIANINHA DIET & Refrigerante \\
\hline 82 & 15201 & GRAPETE DIET & Refrigerante \\
\hline 82 & 15501 & REFRIGERANTE DE ABACATE & Refrigerante \\
\hline 82 & 15601 & REFRIGERANTE DE LARANJA DIET & Refrigerante \\
\hline 82 & 02201 & SUCO DE FRUTA OU VEGETAL ENGARRAFADO & Suco \\
\hline 82 & 02202 & XAROPE DE FRUTA OU VEGETAL ENGARRAFADO & Suco \\
\hline 82 & 02203 & XAROPE DE GUARANA & Suco \\
\hline 82 & 02204 & XAROPE DE GROSELHA & Suco \\
\hline 82 & 02301 & REFRESCO DE FRUTA ENGARRAFADO & Suco \\
\hline 82 & 02302 & REFRESCO DE FRUTA ENCARTONADO & Suco \\
\hline 82 & 02401 & SUCO DE FRUTA OU VEGETAL ARTIFICIAL EM PO & Suco \\
\hline 82 & 02402 & Q-SUCO & Suco \\
\hline 82 & 02403 & Q-REFRESKO & Suco \\
\hline 82 & 02404 & CONCENTRADO DE REFRESCO EM PO & Suco \\
\hline 82 & 02405 & REFRESCO DE FRUTA ARTIFICIAL EM PO & Suco \\
\hline 82 & 02406 & PO DE REFRESCO & Suco \\
\hline 82 & 02407 & REFRESCO ADOCYL EM PO & Suco \\
\hline 82 & 02408 & REFRESCO EM PO & Suco \\
\hline 82 & 02409 & SUCO ARTIFICIAL EM PO & Suco \\
\hline 82 & 02410 & REFRESCO ARTIFICIAL EM PO & Suco \\
\hline 82 & 02411 & QSUCO & Suco \\
\hline 82 & 02412 & SUCO EM PO & Suco \\
\hline 82 & 03801 & REFRESCO EM SACO PLASTICO & Suco \\
\hline
\end{tabular}




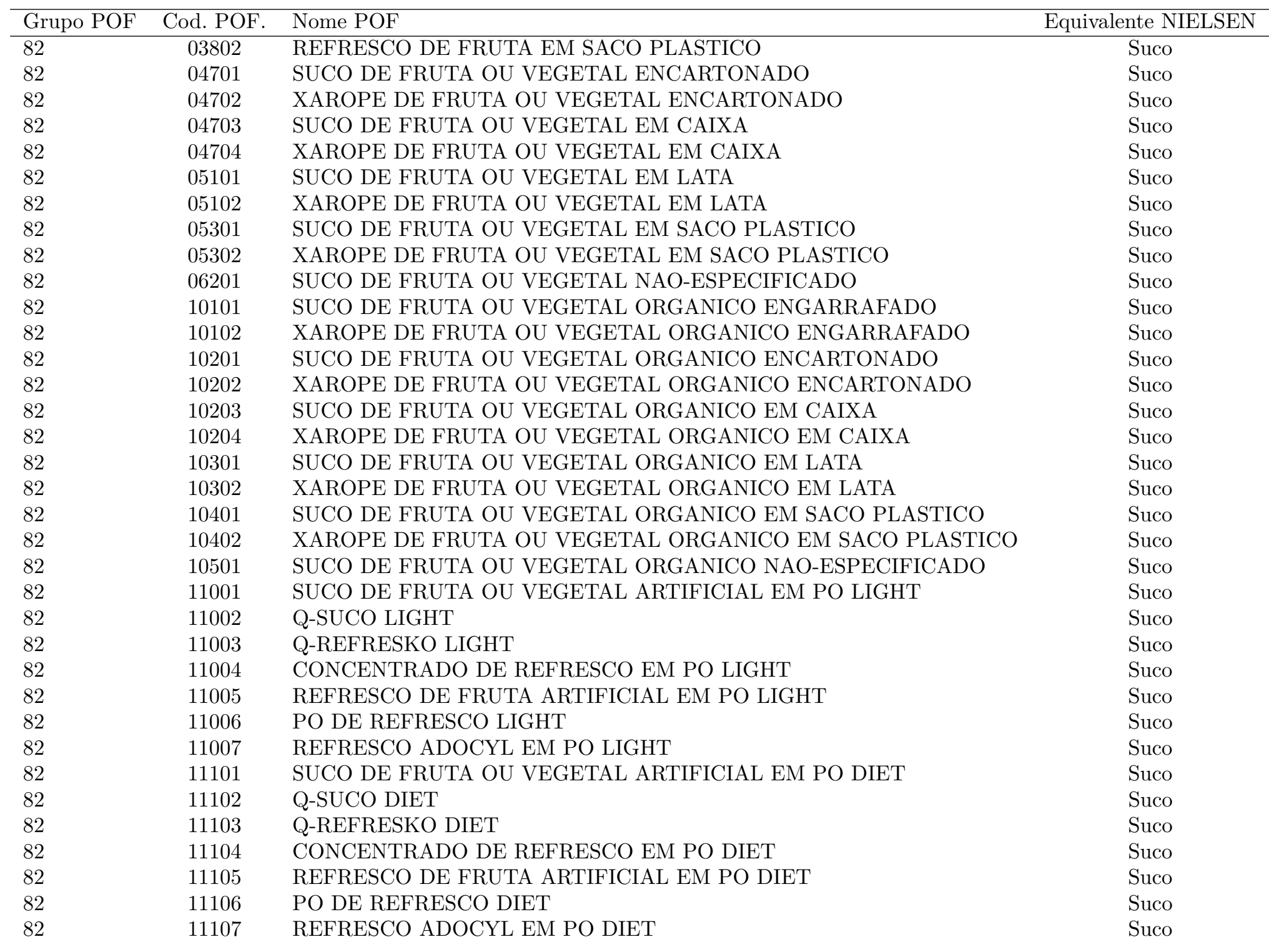




\begin{tabular}{|c|c|c|c|}
\hline Grupo POF & Cod. POF. & Nome POF & Equivalente NIELSEN \\
\hline 82 & 11108 & SUCO DE FRUTA OU VEGETAL ARTIFICIAL EM PO DIETETICO & Suco \\
\hline 82 & 11109 & Q-SUCO DIETETICO & Suco \\
\hline 82 & 11110 & Q-REFRESKO DIETETICO & Suco \\
\hline 82 & 11111 & CONCENTRADO DE REFRESCO EM PO DIETETICO & Suco \\
\hline 82 & 11112 & REFRESCO DE FRUTA ARTIFICIAL EM PO DIETETICO & Suco \\
\hline 82 & 11113 & PO DE REFRESCO DIETETICO & Suco \\
\hline 82 & 11114 & REFRESCO ADOCYL EM PO DIETETICO & Suco \\
\hline 82 & 11401 & SUCO DE FRUTA OU VEGETAL ENGARRAFADO LIGHT & Suco \\
\hline 82 & 11402 & XAROPE DE FRUTA OU VEGETAL ENGARRAFADO LIGHT & Suco \\
\hline 82 & 11501 & SUCO DE FRUTA OU VEGETAL ENGARRAFADO DIET & Suco \\
\hline 82 & 11502 & XAROPE DE FRUTA OU VEGETAL ENGARRAFADO DIET & Suco \\
\hline 82 & 11503 & SUCO DE FRUTA OU VEGETAL ENGARRAFADO DIETETICO & Suco \\
\hline 82 & 11504 & XAROPE DE FRUTA OU VEGETAL ENGARRAFADO DIETETICO & Suco \\
\hline 82 & 11601 & SUCO DE FRUTA OU VEGETAL ENCARTONADO LIGHT & Suco \\
\hline 82 & 11602 & XAROPE DE FRUTA OU VEGETAL ENCARTONADO LIGHT & Suco \\
\hline 82 & 11603 & SUCO DE FRUTA OU VEGETAL EM CAIXA LIGHT & Suco \\
\hline 82 & 11604 & XAROPE DE FRUTA OU VEGETAL EM CAIXA LIGHT & Suco \\
\hline 82 & 11701 & SUCO DE FRUTA OU VEGETAL ENCARTONADO DIET & Suco \\
\hline 82 & 11702 & XAROPE DE FRUTA OU VEGETAL ENCARTONADO DIET & Suco \\
\hline 82 & 11703 & SUCO DE FRUTA OU VEGETAL EM CAIXA DIET & Suco \\
\hline 82 & 11704 & XAROPE DE FRUTA OU VEGETAL EM CAIXA DIET & Suco \\
\hline 82 & 11705 & SUCO DE FRUTA OU VEGETAL ENCARTONADO DIETETICO & Suco \\
\hline 82 & 11706 & XAROPE DE FRUTA OU VEGETAL ENCARTONADO DIETETICO & Suco \\
\hline 82 & 11707 & SUCO DE FRUTA OU VEGETAL EM CAIXA DIETETICO & Suco \\
\hline 82 & 11903 & SUCO DE FRUTA OU VEGETAL EM LATA DIETETICO & Suco \\
\hline 82 & 11904 & XAROPE DE FRUTA OU VEGETAL EM LATA DIETETICO & Suco \\
\hline 82 & 12001 & SUCO DE FRUTA OU VEGETAL EM SACO PLASTICO LIGHT & Suco \\
\hline 82 & 12002 & XAROPE DE FRUTA OU VEGETAL EM SACO PLASTICO LIGHT & Suco \\
\hline 82 & 12101 & SUCO DE FRUTA OU VEGETAL EM SACO PLASTICO DIET & Suco \\
\hline 82 & 12102 & XAROPE DE FRUTA OU VEGETAL EM SACO PLASTICO DIET & Suco \\
\hline 82 & 12103 & SUCO DE FRUTA OU VEGETAL EM SACO PLASTICO DIETETICO & Suco \\
\hline 82 & 12104 & XAROPE DE FRUTA OU VEGETAL EM SACO PLASTICO DIETETICO & Suco \\
\hline 82 & 12201 & SUCO DE FRUTA OU VEGETAL NAO-ESPECIFICADO LIGHT & Suco \\
\hline 82 & 12301 & SUCO DE FRUTA OU VEGETAL NAO-ESPECIFICADO DIET & Suco \\
\hline 82 & 12302 & SUCO DE FRUTA OU VEGETAL NAO-ESPECIFICADO DIETETICO & Suco \\
\hline 82 & 13601 & CLOROFILA (SUCO) & Suco \\
\hline 82 & 14301 & SUCO DE FRUTA OU VEGETAL EM COPO PLASTICO & Suco \\
\hline
\end{tabular}


Tabela 9: POF 2008-2009: Produtos alcoólicos

\begin{tabular}{|c|c|c|c|}
\hline Grupo POF & Cod. POF. & Nome POF & Equivalente NIELSEN \\
\hline 83 & 00101 & CERVEJA & Cerveja \\
\hline 83 & 00102 & CERVEJA PRETA & Cerveja \\
\hline 83 & 00103 & CERVEJA BRANCA & Cerveja \\
\hline 83 & 00201 & CHOPP & Cerveja \\
\hline 83 & 00202 & CHOPP ESCURO & Cerveja \\
\hline 83 & 00203 & CHOPP CLARO & Cerveja \\
\hline 83 & 00204 & CHOPE & Cerveja \\
\hline 83 & 00301 & AGUARDENTE DE CANA & Destilado \\
\hline 83 & 00302 & CACHACA & Destilado \\
\hline 83 & 00303 & DUELO DE CANA COM SABOR DE FRUTA & Destilado \\
\hline 83 & 00304 & AGUARDENTE DE CANA DE ACUCAR & Destilado \\
\hline 83 & 00305 & PINGA & Destilado \\
\hline 83 & 00401 & AGUARDENTE DE UVA & Destilado \\
\hline 83 & 00402 & GRASPA & Destilado \\
\hline 83 & 00403 & BAGACEIRA & Destilado \\
\hline 83 & 00501 & BATIDA DE QUALQUER SABOR & Destilado \\
\hline 83 & 00502 & LEITE DE ONCA & Outro \\
\hline 83 & 00503 & BATIDA DE COCO & Destilado \\
\hline 83 & 00601 & STEINHARGER & Destilado \\
\hline 83 & 00701 & RUM & Destilado \\
\hline 83 & 00801 & VODKA & Destilado \\
\hline 83 & 00901 & GIN & Destilado \\
\hline 83 & 00902 & GENEBRA & Destilado \\
\hline 83 & 01001 & UISQUE & Destilado \\
\hline 83 & 01002 & WHISKY & Destilado \\
\hline 83 & 01101 & CAMPARI & Destilado \\
\hline 83 & 01201 & CHAMPANHE & Vinho \\
\hline 83 & 01202 & SIDRA CHAMPANHE & Vinho \\
\hline 83 & 01301 & VERMUTE & Destilado \\
\hline 83 & 01401 & CINZANO & Destilado \\
\hline 83 & 01501 & MARTINI & Destilado \\
\hline 83 & 01601 & CONHAQUE & Destilado \\
\hline 83 & 01701 & DRINK DREHER & Destilado \\
\hline 83 & 01801 & SAN RAFAEL & Destilado \\
\hline 83 & 01901 & LICOR DE QUALQUER SABOR & Destilado \\
\hline 83 & 02001 & SHERRY & Destilado \\
\hline
\end{tabular}




\begin{tabular}{|c|c|c|c|}
\hline Grupo POF & Cod. POF. & Nome POF & Equivalente NIELSEN \\
\hline 83 & 02501 & AGUARDENTE DE BANANA & Destilado \\
\hline 83 & 02601 & AGUARDENTE DE ALCACHOFRA & Destilado \\
\hline 83 & 02701 & ST. REMY & Destilado \\
\hline 83 & 02801 & KEEP COOLER & Destilado \\
\hline 83 & 02901 & COQUETEL DE FRUTAS & Destilado \\
\hline 83 & 03001 & UNDERBERG & Destilado \\
\hline 83 & 03101 & CAIPIRINHA & Destilado \\
\hline 83 & 03201 & AGUARDENTE DE CATUABA & Destilado \\
\hline 83 & 03301 & CERVEJA SEM ALCOOL & Cerveja \\
\hline 83 & 03401 & TEQUILA & Destilado \\
\hline 83 & 03501 & BEBIDA ALCOOLICA NAO-ESPECIFICADA & Outro \\
\hline 83 & 03701 & AGUARDENTE DE CANA ORGANICA & Destilado \\
\hline 83 & 03702 & CACHACA ORGANICA & Destilado \\
\hline 83 & 03703 & DUELO DE CANA COM SABOR DE FRUTA ORGANICO & Destilado \\
\hline 83 & 03704 & AGUARDENTE DE CANA DE ACUCAR ORGANICA & Destilado \\
\hline 83 & 03801 & AGUARDENTE DE UVA ORGANICA & Destilado \\
\hline 83 & 03802 & GRASPA ORGANICA & Destilado \\
\hline 83 & 03803 & BAGACEIRA ORGANICA & Destilado \\
\hline 83 & 03901 & AGUARDENTE DE ARROZ ORGANICA & Destilado \\
\hline 83 & 03902 & SAQUE ORGANICO & Destilado \\
\hline 83 & 04001 & AGUARDENTE DE BANANA ORGANICA & Destilado \\
\hline 83 & 04101 & AGUARDENTE DE ALCACHOFRA ORGANICA & Destilado \\
\hline 83 & 04201 & AGUARDENTE DE CATUABA ORGANICA & Destilado \\
\hline 83 & 04301 & CERVEJA LIGHT & Cerveja \\
\hline 83 & 04302 & CERVEJA PRETA LIGHT & Cerveja \\
\hline 83 & 04303 & CERVEJA BRANCA LIGHT & Cerveja \\
\hline 83 & 04401 & CERVEJA SEM ALCOOL LIGHT & Cerveja \\
\hline 83 & 04501 & AGUARDENTE DE MANDIOCA & Destilado \\
\hline 83 & 04502 & CAXIRI (AGUARDENTE DE MANDIOCA) & Destilado \\
\hline 83 & 04601 & QUENTAO & Destilado \\
\hline 83 & 04701 & AGUARDENTE DE JALAPA & Destilado \\
\hline 83 & 02101 & FERNET & Destilado \\
\hline 83 & 02201 & BITTER & Destilado \\
\hline 83 & 02301 & AGUARDENTE DE ARROZ & Destilado \\
\hline 83 & 02302 & SAQUE & Destilado \\
\hline 83 & 02401 & VINHO DE UVA E OUTROS & Vinho \\
\hline 83 & 02402 & VINHO ROSE & Vinho \\
\hline
\end{tabular}




\begin{tabular}{|c|c|c|c|}
\hline Grupo POF & Cod. POF. & Nome POF & Equivalente NIELSEN \\
\hline 83 & 03601 & VINHO DE UVA E OUTROS ORGANICO & Vinho \\
\hline 83 & 03602 & VINHO ROSE ORGANICO & Vinho \\
\hline 83 & 03603 & VINHO TINTO ORGANICO & Vinho \\
\hline 83 & 03604 & VINHO VERDE ORGANICO & Vinho \\
\hline 83 & 03605 & VINHO SECO ORGANICO & Vinho \\
\hline 83 & 03616 & CATUABA ORGANICA & Vinho \\
\hline 83 & 03617 & VINHO DE JURUBEBA ORGANICO & Vinho \\
\hline 83 & 02403 & VINHO TINTO & Vinho \\
\hline 83 & 02404 & VINHO VERDE & Vinho \\
\hline 83 & 02405 & VINHO SECO & Vinho \\
\hline 83 & 02406 & VINHO MOSCATEL & Vinho \\
\hline 83 & 02407 & VINHO LICOROSO & Vinho \\
\hline 83 & 02408 & VINHO QUINADO & Vinho \\
\hline 83 & 02409 & CAJUINA (VINHO) & Vinho \\
\hline 83 & 02410 & VINHO BRANCO & Vinho \\
\hline 83 & 02411 & JURUBEBA VINHO & Vinho \\
\hline 83 & 02412 & VINHO DE CATUABA & Vinho \\
\hline 83 & 03606 & VINHO MOSCATEL ORGANICO & Vinho \\
\hline 83 & 03607 & VINHO LICOROSO ORGANICO & Vinho \\
\hline 83 & 03608 & VINHO QUINADO ORGANICO & Vinho \\
\hline 83 & 03609 & CAJUINA ORGANICA & Vinho \\
\hline 83 & 03610 & VINHO BRANCO ORGANICO & Vinho \\
\hline 83 & 03611 & JURUBEBA VINHO ORGANICA & Vinho \\
\hline 83 & 03612 & VINHO DE CATUABA ORGANICO & Vinho \\
\hline 83 & 03613 & VINHO SUAVE ORGANICO & Vinho \\
\hline 83 & 03614 & VINHO DE UVA ORGANICO & Vinho \\
\hline 83 & 03615 & VINHO ORGANICO & Vinho \\
\hline 83 & 02413 & VINHO SUAVE & Vinho \\
\hline 83 & 02414 & VINHO DE UVA & Vinho \\
\hline 83 & 02415 & VINHO & Vinho \\
\hline 83 & 02416 & CATUABA & Vinho \\
\hline 83 & 02417 & VINHO DE JURUBEBA & Vinho \\
\hline
\end{tabular}

